\title{
Mutant $\alpha$-Synuclein Enhances Firing Frequencies in Dopamine Substantia Nigra Neurons by Oxidative Impairment of A-Type Potassium Channels
}

\author{
Mahalakshmi Subramaniam, ${ }^{1}$ DDaniel Althof,, ${ }^{3}$ Suzana Gispert, ${ }^{2}$ Jochen Schwenk, ${ }^{3}$ Georg Auburger, ${ }^{2}$ Akos Kulik, ${ }^{3,4}$ \\ Bernd Fakler, ${ }^{3}$ and Jochen Roeper ${ }^{1}$ \\ ${ }^{1}$ Institute of Neurophysiology, Neuroscience Center, ${ }^{2}$ Department of Neurology, Goethe-University Frankfurt, 60590 Frankfurt, Germany, and ${ }^{3}$ Institute of \\ Physiology II, ${ }^{4}$ BIOSS Centre for Biological Signaling Studies, University of Freiburg, D-79104 Freiburg, Germany
}

Parkinson disease (PD) is an $\alpha$-synucleinopathy resulting in the preferential loss of highly vulnerable dopamine (DA) substantia nigra (SN) neurons. Mutations (e.g., A53T) in the $\alpha$-synuclein gene (SNCA) are sufficient to cause PD, but the mechanism of their selective action on vulnerable DA SN neurons is unknown. In a mouse model overexpressing mutant $\alpha$-synuclein (A53T-SNCA), we identified a $\mathrm{SN}$-selective increase of in vivo firing frequencies in DA midbrain neurons, which was not observed in DA neurons in the ventral tegmental area. The selective and age-dependent gain-of-function phenotype of A53T-SCNA overexpressing DA SN neurons was in part mediated by an increase of their intrinsic pacemaker frequency caused by a redox-dependent impairment of A-type Kv4.3 potassium channels. This selective enhancement of "stressful pacemaking" of DA SN neurons in vivo defines a functional response to mutant $\alpha$-synuclein that might be useful as a novel biomarker for the "DA system at risk" before the onset of neurodegeneration in PD.

Key words: $\alpha$-synuclein; A-type K channel; dopamine; in vivo; redox; substantia nigra

\section{Introduction}

Parkinson disease (PD) is the second most common neurodegenerative disorder (Lees et al., 2009). PD is characterized by the progressive loss of dopamine (DA) substantia nigra (SN) neurons causing its cardinal motor deficits (Lees et al., 2009). The neuropathological hallmark of PD are $\alpha$-synuclein-(SNCA)-positive intracytoplasmic inclusions, the Lewy bodies (Goedert et al., 2013). In familial forms of $\mathrm{PD}$, disease-causing mutations were identified, prominently among them dominant mutations in SNCA (e.g., A53T; Hardy, 2010; Martin et al., 2011). In addition, elevated expression of wild-type $\alpha$-synuclein (by gene multiplication) also causes $\mathrm{PD}$, indicating that overexpression of the wild-type $\alpha$-synuclein is also pathogenic (Hardy, 2010; Martin et al., 2011). Also, genome-wide associations studies have identified common polymorphisms (SNPs) in SNCA as risk factors in sporadic PD (Satake et al., 2009; Simon-Sanchez et al., 2009; Venda et al., 2010).

\footnotetext{
Received Dec. 3, 2013; revised Aug. 18, 2014; accepted Aug. 19, 2014

Author contributions: M.S., A.K., B.F., and J.R. designed research; M.S., D.A., J.S., and J.R. performed research; S.G. and G.A. contributed unpublished reagents/analytic tools; M.S., D.A., J.S., A.K., B.F., and J.R. analyzed data; M.S. and J.R. wrote the paper.

This work was supported by SFB 815 and SFB 1080 project grants to J.R. and BIOSS-2 (TP A6 to A.K.). We thank Beatrice Kern and Annika Parg for their excellent technical support, Pete Magill for sharing his protocol how to juxtacellularly label DA neurons in vivo, Julia Schiemann for teaching M.S. how to use it (Schiemann et al., 2012), and Gaby Schneider for sharing GLO scripts.

The authors declare no competing financial interests.

Correspondence should be addressed to Dr Jochen Roeper, Institute of Neurophysiology, Neuroscience Center, Goethe University Frankfurt, Theodor-Stern-Kai 7, 60590 Frankfurt/Main, Germany. E-mail: roeper@em.uni-franfurt.de.

DOI:10.1523/JNEUROSCI.5069-13.2014

Copyright $\odot 2014$ the authors $\quad 0270-6474 / 14 / 3413586-14 \$ 15.00 / 0$
}

Given these strong genetic links for both familial and sporadic $\mathrm{PD}$, as well as its presence in Lewy bodies, $\alpha$-synuclein is likely to have a central role in the molecular pathogenesis of PD (Venda et al., 2010; Martin et al., 2011). A common pathway might be the generation of toxic $\alpha$-synuclein oligomers, facilitated by SNCA mutations, overexpression, and post-translational modifications (Vekrellis et al., 2011). These toxic $\alpha$-synuclein oligomers have been shown to impair several important cellular functions, among them proteasomal and lysosomal degradation, autophagy and mitophagy, mitochondrial functions, and the redox balance (Topf et al., 2003; Fitch et al., 2006; Vekrellis et al., 2011; Calì et al., 2012; Gan et al., 2012; Siddiqui et al., 2012). However, given the ubiquitous $\alpha$-synuclein expression in the brain, it is still unclear how mutant $\alpha$-synuclein selectively affects the vulnerable subsets of neuronal populations in PD (Goedert et al., 2013), most prominently the DA SN neurons (Fearnley and Lees, 1991; Damier et al., 1999). This selective vulnerability is also found within the dopamine midbrain system, where DA neurons in the ventral tegmental area (VTA) are more resistant compared with those in the SN (Fearnley and Lees, 1991; Damier et al., 1999; Liss et al., 2005; Surmeier et al., 2010).

Current evidence suggests that the innate differences in activity-dependent calcium influx combined with differences in dopamine metabolism generate oxidative loads, that are sufficient to sensitize vulnerable DA SN neurons to $\alpha$-synuclein (i.e., "stressful pacemaker theory"; Sulzer, 2007; Chan et al., 2009). However, it is unknown whether $\alpha$-synuclein itself enhances the differential vulnerability of DA SN neurons. Here, we identify in vivo and in vitro increased action potential firing rates of DA SN 
neurons as a functional response to mutant $\alpha$-synuclein. Furthermore, we show that the frequency increase is caused by a redoxmediated impairment of A-type Kv4.3 potassium (K) channels. Indeed, Kv4.3-mediated A-type K channels control pacemaker frequency in DA SN neurons (Gundersen, 1986; Khaliq and Bean, 2008) and their activity is regulated by a cysteine-mediated redox switch in the T1-assembly domain (Wang et al., 2005, 2007; Wang and Covarrubias, 2006).

\section{Materials and Methods}

Animals and surgery. All experiments and procedures involving mice were approved by the German Regierungspräsidium Darmstadt (V5419c20/15-F40/30). Mouse lines overexpressing A53T-SNCA and their background strain FVB/N (controls: young adult, 3- to 4-months-old; middle-aged, 7- to 10-months-old; Gispert et al., 2003) were used for the experiments.

Male mice were anesthetized using isoflurane (induction 2.5\%, maintenance $0.8-1.4 \%$ in $\mathrm{O}_{2}, 0.35 \mathrm{l} / \mathrm{min}$ ) and were placed in a stereotaxic frame (Kopf). Vidisic (Dr Mann Pharma, Berlin, Germany) was applied on the eyes to prevent the cornea from drying out. Lidocaine gel (Astra Zeneca) was used as a local analgesic at the incision site. Rectal temperature $\left(33-36^{\circ} \mathrm{C}\right)$, heart rate $(5-7 \mathrm{~Hz})$, and respiration $(1-2 \mathrm{~Hz})$ were constantly monitored. Anesthetized animals (Na-pentobarbital, 1.6 $\mathrm{g} / \mathrm{kg}$ ) were transcardially perfused with $4 \%$ paraformaldehyde, $15 \%$ picric acid in PBS, pH 7.4. The perfused brain was stored in PFA overnight and changed to $10 \%$ sucrose and $0.05 \% \mathrm{NaN}_{3}$ solution for longterm storage.

Immunohistochemical stainings. Following in vivo recordings, the anesthetized animals (Na-pentobarbital, $1.6 \mathrm{~g} / \mathrm{kg}$ ) were transcardially perfused with $4 \%$ paraformaldehyde, $15 \%$ picric acid in PBS, $\mathrm{pH}$ 7.4. Brains were postfixed overnight and coronal midbrain sections (30 $\mu \mathrm{m}$ for stereological counting and $60 \mu \mathrm{m}$ for immunofluorescence) were prepared (VT1000S microtome, Leica). Sections were rinsed in PBS and then incubated in a blocking solution ( $0.2 \mathrm{M}$ PBS with $10 \%$ horse serum, $0.5 \%$ Triton X-100, 0.2\% BSA). The following primary antibodies were used (in carrier solution, $22^{\circ} \mathrm{C}$, overnight): polyclonal rabbit anti-tyrosine hydroxylase (TH; 1:1000; Calbiochem, Merck), anti-mouse TH (1:1000; Millipore), rabbit anti-rat Kv4.3 (1:1000, Alomone Labs), monoclonal mouse anti- $\alpha$-synuclein ${ }_{\mathrm{h}}$ (human, 4B12, Thermo Fisher Scientific). The following secondary antibodies (in carrier solution, $22^{\circ} \mathrm{C}$, overnight): AlexaFluor-488 goat anti-rabbit and AlexaFluor-647 goat anti-mouse (all 1:750; Life technologies). Streptavidin AlexaFluor-568 (1:1000; Molecular Probes) was used. Sections were rinsed in PBS and mounted on slides (Vectashield, Vector Laboratories). Multilabeling fluorescent immunostainings of juxtacellularly filled neurons were analyzed using a laser-scanning microscope (LSM 510 Meta, Zeitz; or Nikon Eclipse90i, Nikon $\mathrm{GmbH}$ ) using either $109 / 0.3$ or $609 / 1.4$ or $639 / 1.4$ differential interference contrast lens $(10 \times$ zoom $)$. For semiquantitative expression analysis of the mutant human $\alpha$-synuclein transgene in DA SN and DA VTA neurons, we determined the mean immunosignal intensities of THpositive regions-of-interest (ROIs) in the midbrain using ImageJ software (http://rsbweb.nih.gov/ij/). For semiquantitative expression analysis of the Kv4.3 subunit in in DA SN and DA VTA neurons, we determined the mean immunosignal intensities of TH-positive ROIs in the midbrain using ImageJ software (http://rsbweb.nih.gov/ij/).

In vivo electrophysiology. In vivo extracellular single unit activities of SN and VTA neurons were recorded in A53T-SNCA mice and their controls. The procedure was similar as described previously (Schiemann et al., 2012). Briefly, the anesthetized (isoflurane; induction $2.5 \%$, maintenance $0.8-1.4 \%$ in $\mathrm{O}_{2}, 0.35 \mathrm{l} / \mathrm{min}$ ) mice (premedicated with $0.1 \mathrm{mg} / \mathrm{kg}$ atropine) were placed into a stereotactic frame (Kopf). The craniotomies were created corresponding to the midbrain regions using the following coordinates [lateral $(x)$, posterior $(y)$, and ventral $(z)$ to bregma, in $\mathrm{mm}$ ]: $y$-coordinates were adjusted according to skull size [in mm, $y=(-3.08 /$ $4.2 \times$ distance (bregma-lambda) -0.3 ), medial SN: $x=0.9, y=\sim-3.2$, $z=4.1$; lateral SN: $x=1.4, y=-3.2, z=3.9$. VTA was targeted using the following coordinates: $x=0.75, y=\sim-3.2, z=3.9$. The coordinates were according to the mouse brain atlas (Franklin and Paxinos, 2008).
Micromanipulator (SM-6, Luigs and Neumann) was used to lower the electrodes to the recording site. Glass electrodes (12-22 M $\Omega$; Harvard Apparatus) filled with $0.5 \mathrm{~m} \mathrm{NaCl}, 10 \mathrm{~mm}$ HEPES, $1.5 \%$ neurobiotin (Vector Laboratories) were used for recording. The extracellular singleunit activity was recorded for $10 \mathrm{~min}$ and the signals were acquired with EPC-10 A/D converter (PatchMaster software, Heka; sampling rate 12.5 $\mathrm{kHz}$ for spike train analyses and $20 \mathrm{kHz}$ for AP waveform analyses). The extracellular signals were amplified 1000× (ELC-03M, NPI Electronics), notch- and bandpass-filtered $0.3-5 \mathrm{kHz}$ (single-pole, $6 \mathrm{~dB}$ /octave, DPA2FS, NPI Electronics). Simultaneously, the signals were displayed on an analog oscilloscope and an audio monitor. Midbrain DA neurons were electrophysiologically identified by their broad biphasic action potential $(>1.2 \mathrm{~ms})$, slow-frequency $(1-8 \mathrm{~Hz})$ and their firing pattern (regular, irregular, and bursting; Grace and Bunney, 1984; Ungless et al., 2004). The classical 80/160 ms criterion was used for burst detection (Grace and Bunney, 1984). IgorPro 6.02 (WaveMetrics) and R statistical computing (www.r-project.org) software were used for the data analysis.

Juxtacellular labeling of single neurons. To identify the anatomical location and neurochemical identity of the recorded neuron, following extracellular single-unit recordings, the neurons were labeled with neurobiotin using juxtacellular in vivo labeling technique (Pinault, 1996). Microiontophoretic current was applied (1-10 nA positive current, 200 ms on/off pulse, ELC-03M; EPC-10, NPI Electronics, as external trigger) via the recording electrode with continuous monitoring of the singleunit activity. The labeling event was considered successful when the firing pattern of the neuron was modulated during current injection (i.e., increased activity during on-pulse and absence of activity in the off-pulse) and the process was stable for minimum $25 \mathrm{~s}$ followed by the spontaneous activity of the neuron after modulation. This procedure resulted in the exact mapping of the recorded DA neuron within the SN subnuclei (Franklin and Paxinos, 2008) along with the neurochemical identification of TH immunostainings.

In vitro electrophysiology. Coronal midbrain sections $(250 \mu \mathrm{m})$ were used for recording the DA SN neurons from middle-aged A53T-SNCA mice and age-matched controls. The midbrain slices were sectioned after intracardial perfusion using ice-cold ACSF (50 mM sucrose, $125 \mathrm{~mm}$ $\mathrm{NaCl}, 2.5 \mathrm{~mm} \mathrm{KCl}, 25 \mathrm{~mm} \mathrm{NaHCO} 3,1.25 \mathrm{~mm} \mathrm{NaH}_{2} \mathrm{PO}_{4}, 2.5 \mathrm{~mm}$ glucose, $6.2 \mathrm{~mm} \mathrm{MgCl} 2,0.1 \mathrm{~mm} \mathrm{CaCl} 2$, and $2.96 \mathrm{~mm}$ kynurenic acid; SigmaAldrich $\mathrm{GmbH}$ ), oxygenated with $95 \% \mathrm{O}_{2} / 5 \% \mathrm{CO}_{2}$ ). Slices were continuously perfused with oxygenated ACSF $\left(2-4 \mathrm{ml} \mathrm{min}^{-1}, 36^{\circ} \mathrm{C} ; 22.5 \mathrm{~mm}\right.$ sucrose, $125 \mathrm{~mm} \mathrm{NaCl}, 2.5 \mathrm{~mm} \mathrm{KCl}, 25 \mathrm{~mm} \mathrm{NaHCO} 3,1.25 \mathrm{~mm} \mathrm{NaH}_{2} \mathrm{PO}_{4}$, $2.5 \mathrm{~mm}$ glucose, $2.1 \mathrm{~mm} \mathrm{MgCl} 2$, and $2 \mathrm{~mm} \mathrm{CaCl} 2 ; 95 \% \mathrm{O}_{2} / 5 \% \mathrm{CO}_{2}$ ) for $\geq 90 \mathrm{~min}$ and then transferred to a recording chamber. CNQX (12.5 $\mu \mathrm{M}$; Biotrend) and gabazine (SR95531, $4 \mu \mathrm{M}$; Biotrend) were added to inhibit fast excitatory and inhibitory synaptic transmission, respectively. The electrophysiological recordings (whole-cell and nucleated outside-out recordings) and data acquisition was performed as previously described (Liss et al., 2001). ACSF containing $400 \mu \mathrm{m} 4$-aminopyridine (4-AP; Tocris Bioscience) was applied to the bath. $200 \mu \mathrm{l}$ of $10 \mu \mathrm{M}$ phrixotoxin-2 solution was applied to the bath (volume $1.8 \mathrm{ml}$ ) to achieve a final concentration of $1 \mu \mathrm{m}$ phrixotoxin-2 (Alomone Labs) for selective inhibition of Kv4 channels. Pipette solutions containing $10 \mathrm{~mm}$ glutathione were dialyzed into SN DA neurons in the whole-cell configuration to test for redox modulation of $\mathrm{Kv} 4$ channels.

Pre-embedding and SDS-FRL. Immunocytochemical labeling for electron microscopy was performed as described previously (Kulik et al., 2006; Masugi-Tokita and Shigemoto, 2007). Briefly, young adult wildtype (WT; $\mathrm{N}=3$ ) and A53T-SNCA transgenic $(\mathrm{N}=3)$ mice were anesthetized with sodium pentobarbital $(90 \mathrm{mg} / \mathrm{kg}$, i.p), and perfused transcardially with $25 \mathrm{~mm}$ PBS, followed by a fixative solution containing $4 \%$ paraformaldehyde, $0.05 \%$ glutaraldehyde and $15 \%$ picric acid for pre-embedding immunogold labeling or $2 \%$ paraformaldehyde and $15 \%$ picric acid for SDS-digested freeze-fracture replica immunolabeling (SDS-FRL). Brains were surgically removed and sections from SN were cut at a thickness of $50 \mu \mathrm{m}$ for pre-embedding immunogold-labeling, and $90 \mu \mathrm{m}$ for SDS-FRL, respectively. For pre-embedding immunogoldlabeling slices were incubated with primary antibody (Kv4.3; $3.0 \mu \mathrm{g} / \mathrm{ml}$; Alomone Labs) followed by incubation with $1.4 \mathrm{~nm}$ gold-coupled secondary antibody (1:100, Nanogold, Nanoprobes) and treated with HQ 
A

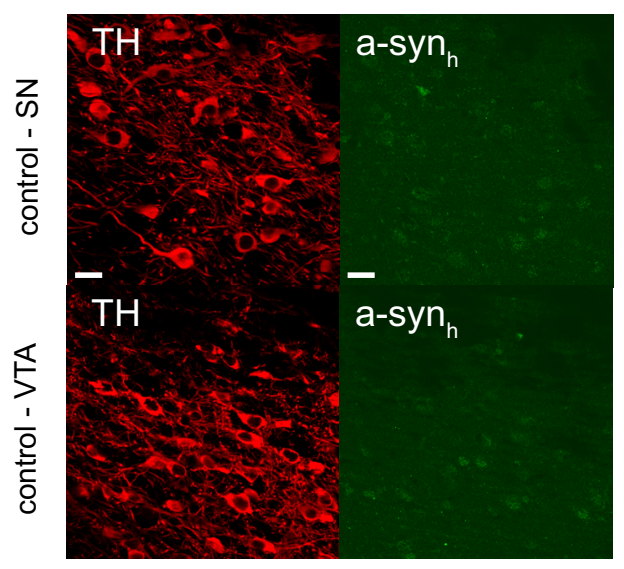

C

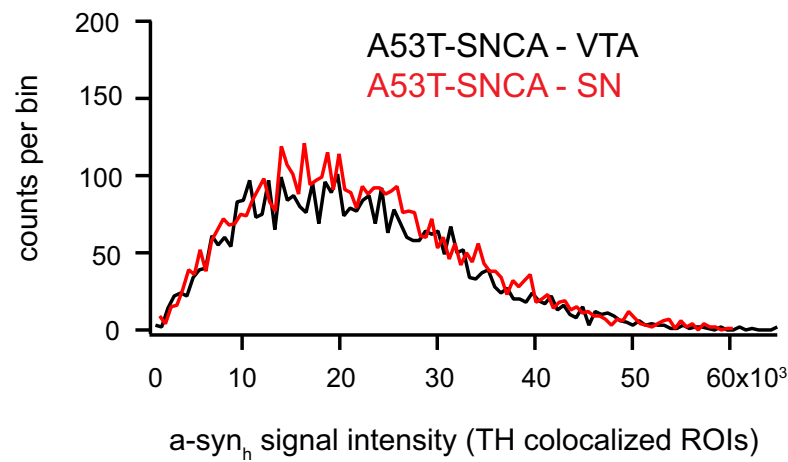

B

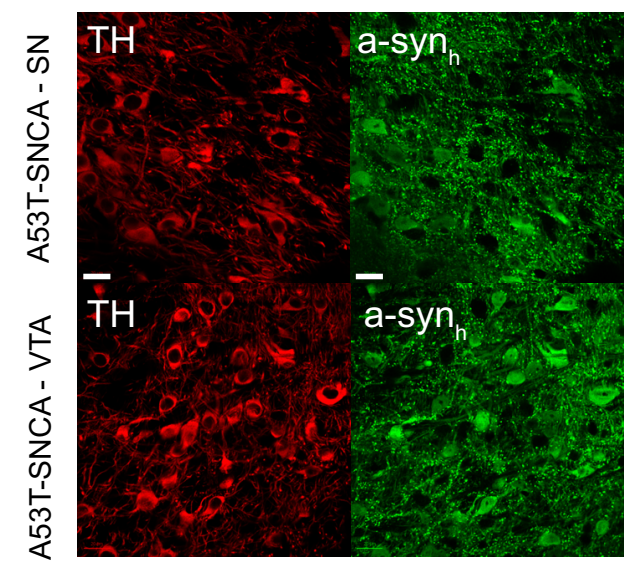

D

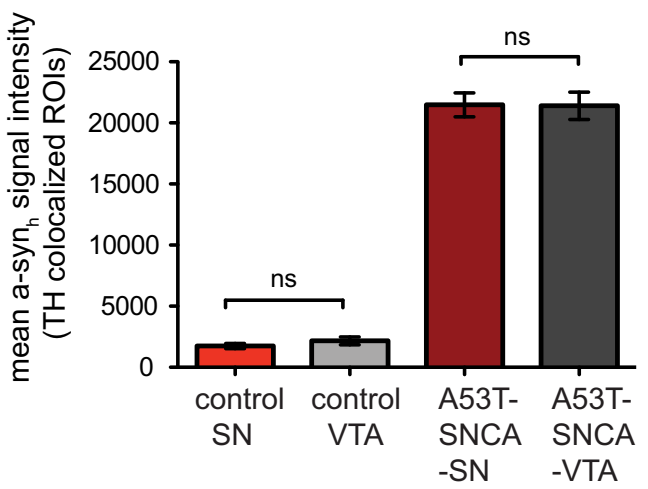

Figure 1. Similar expression of human $\alpha$-synuclein in SN DA and VTA DA neurons. $\boldsymbol{A}, \boldsymbol{B}$, Confocal images at high-magnification (60X oil) showing TH-positive signal (red) and human $\alpha$-synuclein-positive signal (a-syn $n_{h}$ green) in SN and VTA midbrain regions of control $(\boldsymbol{A})$ and A53T-SNCA mice $(\boldsymbol{B})$, respectively. Scale bar, $20 \mu \mathrm{m}$. $\boldsymbol{C}$, Histogram showing the distributions of human $\alpha$-synuclein immunosignal intensities, measured for TH-colocalized ROIs, in DA SN (red) and DA VTA (black) neurons of A53T-SNCA mice. $D$, Comparison of the mean \pm SEM a-syn ${ }_{h}$ immunosignal (TH-colocalized ROIs) from DA SN and DA VTA neurons in control and A53T-SNCA mice, respectively. ns, Not significant; Mann-Whitney test.

Silver kit (Nanoprobes). After osmification, slices were contrasted using uranylacetate, dehydrated, and embedded in Durcupan resin (Fluka). Ultrathin sections were cut at a thickness of $60 \mathrm{~nm}$ and sections were analyzed in an electron microscope (Philips CM100). For SDS-FRL, the slices were cryoprotected in a solution containing 30\% glycerol then were frozen by a high-pressure freezing machine (HPM 100, Leica). Frozen samples were fractured at $-130^{\circ} \mathrm{C}$ and replicated by carbon deposition ( 5 $\mathrm{nm}$ thick), platinum $(2 \mathrm{~nm})$, and carbon $(18 \mathrm{~nm})$ in a freeze-fracture replica machine (BAF 060; BAL-TEC). Replicas were then incubated in a digestion buffer containing $2.5 \%$ SDS, $20 \%$ sucrose in $15 \mathrm{~mm}$ Tris- $\mathrm{HCl}$, $\mathrm{pH} 8.6$, at $80^{\circ} \mathrm{C}$ for $18 \mathrm{~h}$. Replicas were washed in $50 \mathrm{~mm}$ TBS containing $0.05 \%$ bovine serum albumin (BSA) and $0.1 \%$ Triton X-100 (Tx) and then incubated in a blocking solution containing 5\% BSA and $0.1 \%$ Tx for $1 \mathrm{~h}$. Subsequently, replicas were incubated in primary antibody (Kv4.3, $0.6 \mathrm{mg} / \mathrm{ml}$; Alomone Labs) made up in $50 \mathrm{~mm}$ TBS containing $1 \%$ BSA and $0.1 \%$ Tx overnight at room temperature (RT). After several washes, replicas were reacted with gold-coupled $(10 \mathrm{~nm})$ goat anti-rabbit secondary antibody (1:30; BioCell Research Laboratories) made up in 50 mM TBS containing 5\% BSA for $2 \mathrm{~h}$ at RT. They were then washed and picked up on 100-mesh grids. The labeled replicas were examined using a transmission electron microscope and dendritic shafts showing immunoreactivity for Kv4.3 in the SN pars compacta photographed at a magnification of 9.500. The surface density of immunogold particles for the channel protein was calculated by dividing the absolute number of particles by the surface of the respective dendritic shafts obtained from WT ( $n=36$ dendrites) and transgenic $(n=46$ dendrites $)$ animals. Data from two WT and two A53T-SNCA animals were pooled together because no statistical ( $t$ test) significance was detected. Difference between the two groups was judged to be significant $(t$ test $)$ at $p<0.002$.

Statistics. The scatter plots are represented with median or mean \pm SEM, and the bar graphs are represented with mean \pm SEM. The statistical significance was evaluated using nonparametric $t$ test (Mann-Whitney test) and one-way ANOVA. The resulting $p$ values were compared with Bonferroni-corrected $\alpha$-level or Tukey post hoc comparison. A value of $p \leq 0.05$ was considered to be statistically significant; $p \leq 0.05={ }^{*} p \leq$ $0.005={ }^{* *} p \leq 0.0005={ }^{* *}$. Graphs were plotted using GraphPad Prism software $(5.0 \mathrm{c})$.

\section{Results}

No differences in mutant $\alpha$-synuclein expression between middle-aged DA SN and DA VTA midbrain neurons in the A53T-SNCA mouse model

To study the in vivo physiology of DA midbrain neurons in young adult (3-4 months) and middle-aged (7-8 months) male mice, we used a well characterized transgenic mouse model of PD, where mutant human $\alpha$-synuclein (A53T-SNCA) is overexpressed $\approx 1.5$-fold in the DA SN neurons under control of the prion promoter (Gispert et al., 2003). These A53T-SNCA mouse lines show progressive changes of vertical motor activity starting between 3 and 6 months (Gispert et al., 2003), increased openfield activity at 6 month of age (Paumier et al., 2013), reduced axonal dopamine release in mice from an age of 18 months (Platt 
control

A

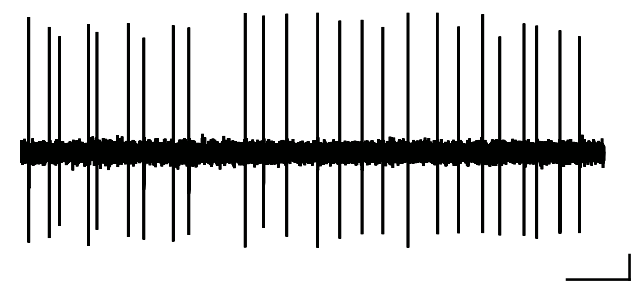

|| || | || |||| ||| || || || ||| || || ||| || ||

| || |||| || || ||| || | || | |||| || || || ||

|| || || | || || | || || || |||| || | || | | ||
B

\section{A53T-SNCA}

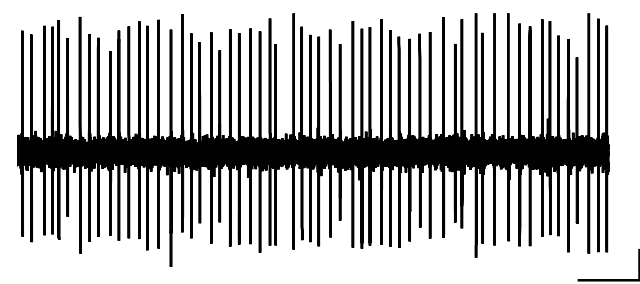

|| || || || |||||||||||||||||||||||||||||||| ||| ||||||||||||||||||||| ||||||||

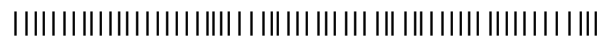

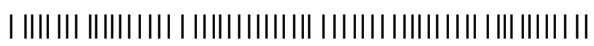

C

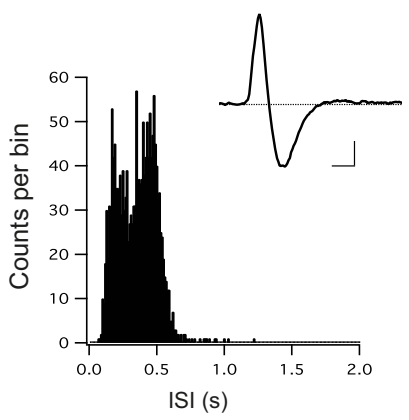

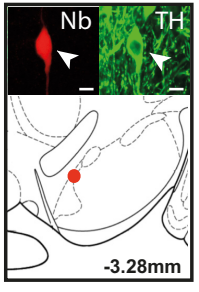

D

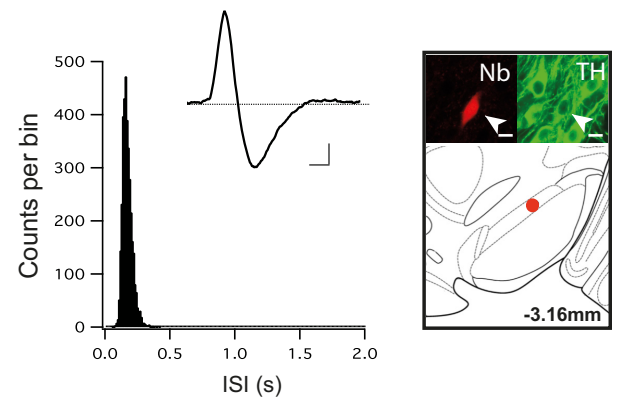

E

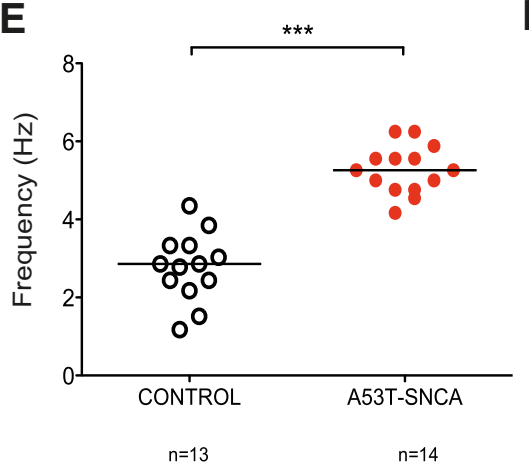

H

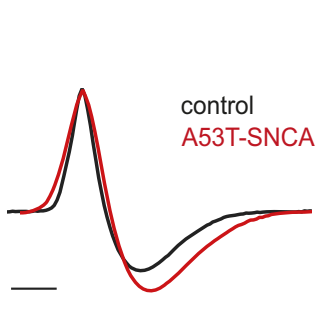

F

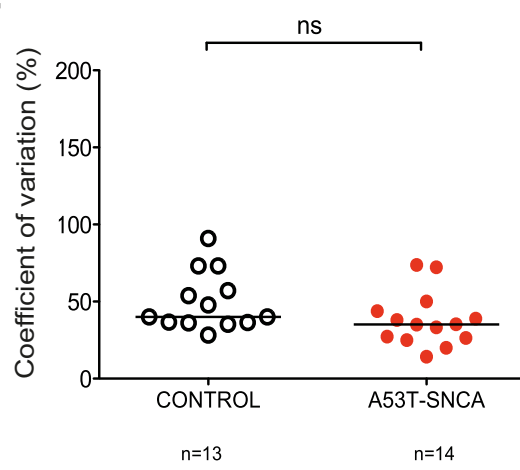

G

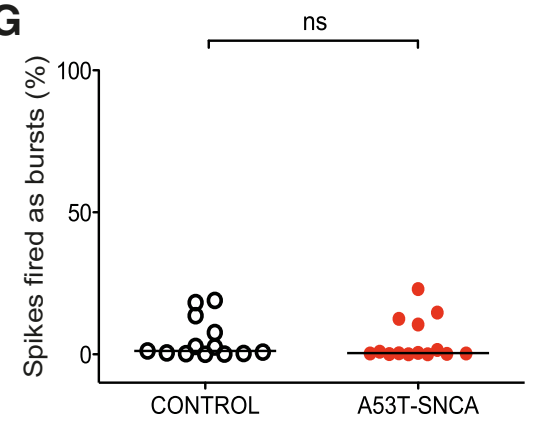

$n=13$

$n=14$
I

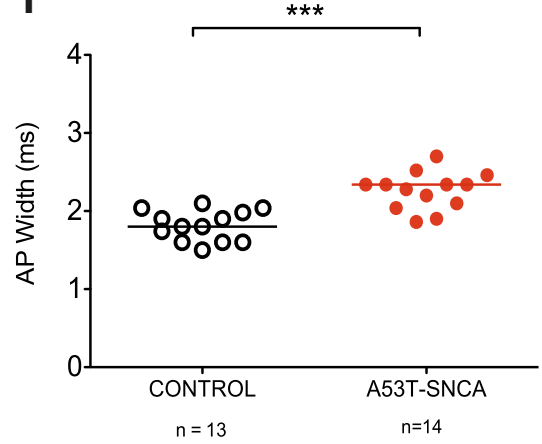

J

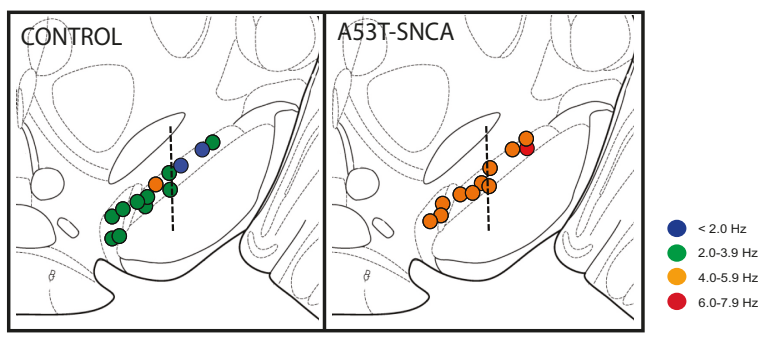

Figure 2. DA SN neurons in middle-aged A53T-SNCA mice show increased in vivo firing frequencies. $\boldsymbol{A}, \boldsymbol{B}$, Spontaneous extracellular in vivo single unit activity of identified DA SN neurons, shown as 10 s original recording trace, in control $(\boldsymbol{A})$ and A53T-SNCA mice ( $\boldsymbol{B}$; Scale bar, $0.2 \mathrm{mV}, 1 \mathrm{~s})$ following 30 s raster plot (Scale bar, $1 \mathrm{~s})$ of the DA SN neurons of the control (bottom left) and A53T-SNCA mice (bottom right). Note the change in the firing frequency between the two groups. $\boldsymbol{C}, \boldsymbol{D}$, ISIHs depict the pattern of firing of the DA SN neurons in the control ( $\boldsymbol{C}$ ) and A53T-SNCA mice ( $\boldsymbol{D})$. Inset, Averaged waveform showing biphasic extracellular action potential in high resolution (Scale bar, $0.2 \mathrm{mV}, 1 \mathrm{~ms}$ ) with corresponding confocal laser-scanning microscopy (CLSM) images of juxtacellularly labeled single DA SN neuron with multilabeling immunocytochemistry in the two groups, respectively (green, $\mathrm{TH}$; red, Nb). Scale bar, $10 \mu \mathrm{m}$. Bottom, Map showing the location of juxtacellularly labeled single recorded rostral DA SN neuron. $\boldsymbol{E}-\mathbf{G}$, Scatter dot-plot showing significant increase in the in vivo firing frequency of the DA SN neurons in the (Figure legend continues.) 
et al., 2012), and late onset enhancement of striatal dopamine content (Kurz et al., 2010), but no obvious degeneration of DA SN neurons (Gispert et al., 2003). Therefore, this particular A53T-SNCA mouse model might present preclinical and early stages of PD before the occurrence of significant neuronal loss but with age-dependent progressive neural dysfunctions. To ensure that the two dopaminergic target populations in the SN and VTA had a similar expression of the mutant $\alpha$-synuclein, we used a monoclonal antibody (mAB 4B12) that selectively detects the human $\alpha$-synuclein but does not cross-react with the endogenous mouse $\alpha$-synuclein. As shown in Figure 1A, we observed only background staining using this human $\alpha$-synuclein-specific $\mathrm{mAB}$ in the SN or VTA of control mice. In contrast, we detected strong immunosignals of human $\alpha$-synuclein in both TH-positive DA SN and DA VTA neurons in middle-aged A53T-SCNA mice. Figure $1 C$, demonstrates that the human $\alpha$-synuclein signal intensity distributions of TH-positive neurons in the SN and VTA were almost identical. This is also reflected in the very similar mean human $\alpha$-synuclein signal intensities between DA SN and DA VTA neurons (Fig. 1D). Furthermore, the mean signal intensities were independent of the sizes of the identified TH-positive regions both in SN and VTA indicating that the expressed transgene did not accumulate in one particular somatodendritic domain (data not shown). In summary, the similar expression levels of mutant $\alpha$-synuclein in DA SN and DA VTA neurons in this particular A53T-SNCA mouse model renders it suitable for a comparative electrophysiological in vivo study.

\section{Increased in vivo firing frequencies in middle-aged DA SN neurons of A53T $\alpha$-synuclein-expressing mice}

We recorded extracellular in vivo single-unit activity of DA SN and DA VTA neurons in anesthetized A53T-SNCA and agematched controls (age 3-4 months and 7-10 months). Importantly, all in vivo recorded and analyzed neurons in this study $(n=70)$ were successfully juxtacellularly labeled with neurobiotin in vivo and post hoc immunohistochemically identified as dopaminergic (i.e., TH-positive). The neurobiotin-labeling also allowed unequivocal anatomical mapping of DA neurons with the midbrain (Ungless et al., 2004; Schiemann et al., 2012). Figure $2 A-D$, compares two representative examples of spontaneous in vivo activity of juxtacellularly labeled and immunohistochemically identified DA SN neurons in middle-aged (7-10 month) control and A53T-SNCA mice. Electrical activity is shown in the top of Figure $2 A, B$, as $10 \mathrm{~s}$ traces of original data and below on a compressed time scale ( $30 \mathrm{~s}$ raster plots). The approximately twofold higher mean in vivo discharge frequency of the A53T-SNCA DA SN neuron is notable compared with the control. This is also apparent in the respective interspike interval histograms (ISIHs; Fig. $2 C, D$ ), which capture the entire recording time of $10 \mathrm{~min}$. In addition, the action potential (AP) waveforms from A53T-SNCA and control DA SN neurons showed differences with a signifi-

(Figure legend continued.) A53T-SNCA mice (E). No significant difference is observed in the CV $(\boldsymbol{F})$, and the number of SFBs $(\boldsymbol{G})$ within the two groups, respectively. $\boldsymbol{H}$, Overlaid plot of mean averaged action potential waveforms (normalized to 1) of DA SN neurons from middle-aged A53T-SNCA mice (red) and age-matched controls (black) recorded in vivo. Scale bar, 1 s. I, Scatter dot-plot of action potential duration of DA SN neurons of middle-aged A53T-SNCA and age-matched control mice, recorded in vivo. J, Frequency distribution map. The in vivo firing frequency of each DA SN neuron is color-coded (legend gives the frequency range) in the control and A53T-SNCA mice, respectively. Note that the DA SN neurons in the A53T-SNCA mice have high discharge frequencies. Line in the scatter dot-plot represents the median. Mann-Whitney test; ${ }^{* * *} p<0.0005,{ }^{*} p<0.05$. cantly prolonged AP repolarization phase in A53T-SNCA (Fig. $2 C, D, H$, insets; mean AP width, ms, control: $1.8 \pm 0.06, n=13$, $N=4$; A53T-SNCA: $2.3 \pm 0.07, n=14, N=4, p=0.0003$, Mann-Whitney $U$ ). The confocal images in Figure 2C,D, demonstrate that the recorded and neurobiotin $(\mathrm{Nb})$-labeled neurons (top, left) were (TH)-immunopositive, i.e., dopamine neurons (top, right) and located in the SN (bottom).

Figure $2 E$, plots the mean firing frequencies of all in vivo recorded, labeled, and identified DA SN neurons from middle-aged controls and A53T-SNCA mice. Each neuron was recorded continuously at least for $10 \mathrm{~min}$ before labeling. The mean in vivo firing frequencies of A53T-SNCA DA SN neurons was almost twofold $(+89 \%)$ higher compared with that from DA SN neurons in control mice (Fig. 2E; control: $2.8 \pm 0.3 \mathrm{~Hz}, n=13, N=$ 4; A53T-SNCA: $5.3 \pm 0.2 \mathrm{~Hz}, n=14, N=4, p<0.0001$, MannWhitney test). In contrast to the large differences in mean firing frequencies and the differences in action potential waveforms (Fig. $2 \mathrm{H}, \mathrm{I}$; mean AP width, ms: control: $1.8 \pm 0.06, n=13, N=$ 4; A53T-SNCA, $2.3 \pm 0.07, n=14, N=4, p=0.0003$, MannWhitney $U$ ), we found no significant change in the overall regularity of discharge, expressed as the coefficient-of-variation $(\mathrm{CV}=\mathrm{SD} /$ mean $)$. The $\mathrm{CV}$ was very similar in the two groups of DA SN neurons indicating that those from A53T-SNCA reduced their interspike variability in proportion to their shorter interspike durations (Fig. 2F; control: $50 \pm 5 \%, n=13, N=4$; A53T-SNCA: $38 \pm 5 \%, n=14, N=4, p=0.05$, Mann-Whitney test). In vivo, DA $\mathrm{SN}$ neurons spontaneously switch between lowfrequency single spike firing and high-frequency burst firing (Grace and Bunney, 1984; Schiemann et al., 2012). Using a conventional burst detection paradigm $(80 \mathrm{~ms} / 160 \mathrm{~ms}$ criteria; Grace and Bunney, 1984), we did not detect differences in burstiness (percentage of spikes fired as bursts; $\mathrm{SFB}$ ) between the two groups of DA SN neurons (Fig. $2 G$; control: $5.2 \pm 2 \%, n=13, N=4$; A53T-SNCA: $5.0 \pm 2 \%, n=14, N=4 ; p=0.53$, Mann-Whitney test). Further analysis of overall spike pattern based on our previously established GLO-model, which quantitatively describes the autocorrelogram of DA neuronal spiketrains (Bingmer et al., 2011; Schiemann et al., 2012), showed a significant shift toward pacemaker pattern compared with irregular single spike or burst pattern in the DA SN neurons of A53T-SNCA mice compared with controls (controls: pacemaker $=15 \%, n=13$; A53T-SNCA neurons: pacemaker $=79 \%, n=14 ; p=0.0081, \chi^{2}$ test).

Figure $2 J$, plots the mediolateral distribution of mean firing frequencies recorded in DA SN neurons from middle-aged controls and A53T-SNCA mice, respectively. Mean discharge frequencies are color-coded and demonstrate that regardless of the medial-to-lateral position, all DA SN neurons in the A53T-SNCA mice were homogeneously affected in their discharge frequencies. In summary, we identified a frequency-selective enhancement of in vivo excitability accompanied by a delayed action potential repolarization in middle-aged DA SN neurons in the A53T-SNCA mice.

\section{Electrical in vivo activity of DA VTA neurons is not altered in middle-aged A53T-SNCA mice}

DA VTA neurons are relatively resistant in PD (Fearnley and Lees, 1991; Damier et al., 1999) and its animal models (Liss et al., 2005; Surmeier and Schumacker, 2013). We investigated whether labeled and neurochemically identified DA VTA neurons in the A53T-SNCA mice also displayed altered in vivo excitability given that they express similar levels of mutant $\alpha$-synuclein (see above). We focused on the rostral VTA, where DA neurons possess similar electrophysiological properties to those in the SN (Lammel et 
A

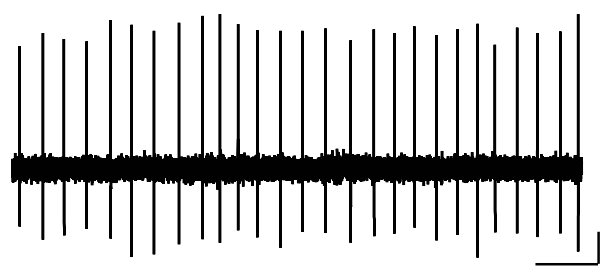

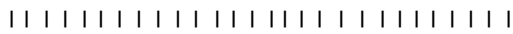

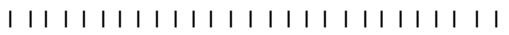

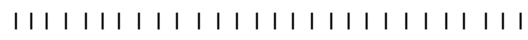

C

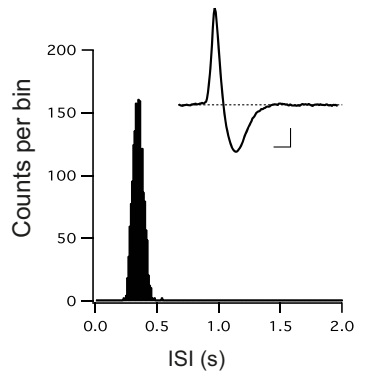

E

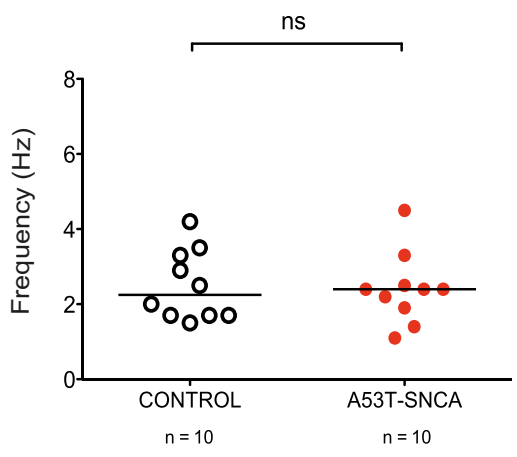

B

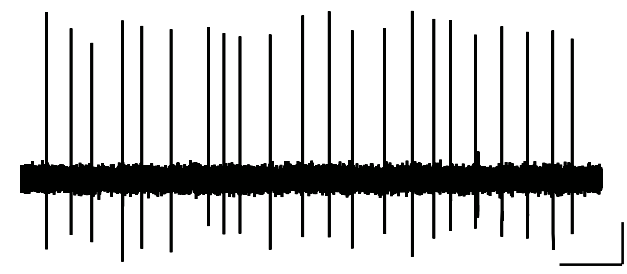

D

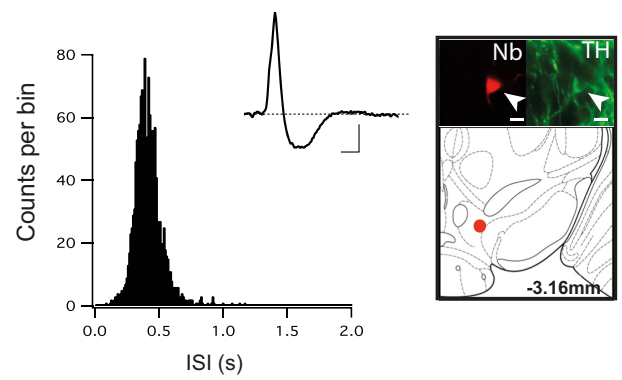

$\mathbf{F}$

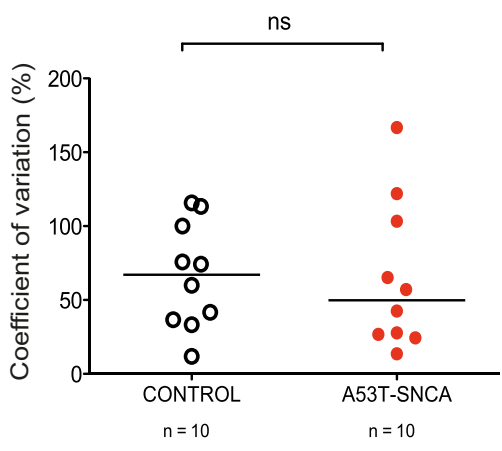

G
A53T-SNCA

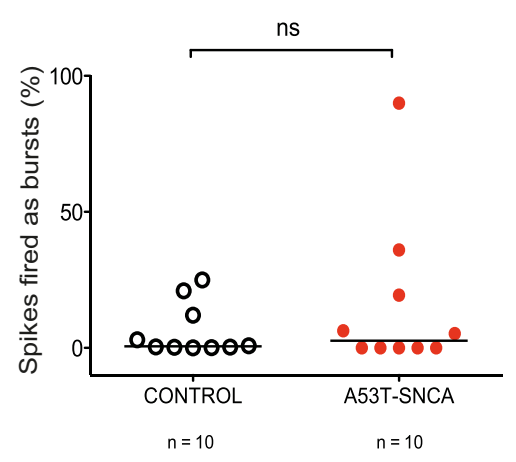

H

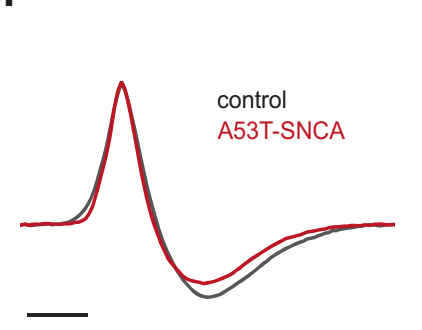

I

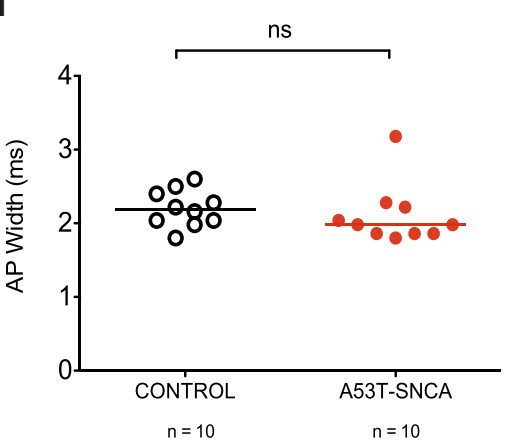

J

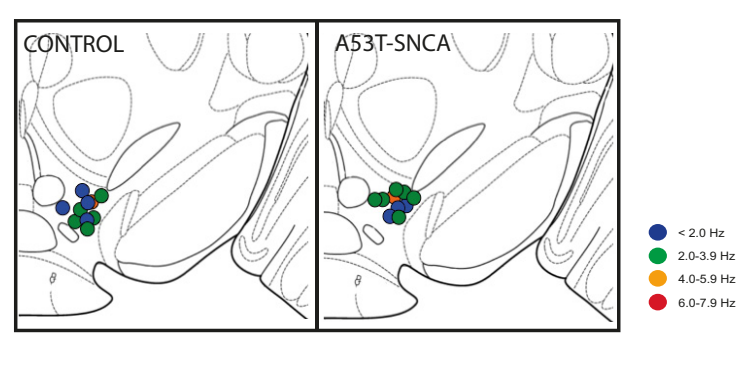

Figure 3. The in vivo activity of DA VTA neurons in middle-aged A53T-SNCA mice is not different from controls. $A, B$, Spontaneous extracellular in vivo single unit activity of identified rostral VTA (r-VTA) DA neurons, shown as $10 \mathrm{~s}$ original trace, in control $(\boldsymbol{A})$, and A53T-SNCA $(\boldsymbol{B})$, respectively, (Scale bar, $0.2 \mathrm{mV}, 1 \mathrm{~s})$ with corresponding $30 \mathrm{~s}$ raster plot at the bottom. Scale bar, 1 S. C, D, ISIH depicting the pattern of firing in the r-VTA DA neurons in the control $(\boldsymbol{C})$ and A53T-SNCA mice $(\boldsymbol{D})$ with respective averaged biphasic waveform (inset). Scale bar, $0.2 \mathrm{mV}, 1 \mathrm{~ms}$. CLSM of respective juxtacellularly labeled single r-VTA DA neuron along with multilabeling immunocytochemistry (bottom). The Nb-filled neurons (red) expressed TH (green) and were located in the r-VTA. Scale bar, $10 \mu \mathrm{m}$. Right, Map showing the location of juxtacellularly labeled single recorded r-VTA DA neuron (bregma $-3.08 \mathrm{and}-3.28 \mathrm{~mm}$, respectively). $\boldsymbol{E}$, In vivo firing frequency of the r-VTA DA neurons is not changed between control and A53T-SNCA mice. $F$, $G$, Shows no significant changes in the coefficient of variation and the SFB. $\boldsymbol{H}$, Overlaid plot of mean averaged action potential waveforms (normalized to 1) of DA VTA neurons from middle-aged A53T-SNCA mice (red) and age-matched controls (black) recorded in vivo. Scale bar, 1 s. I, Action potential duration of DA VTA neurons in controls and middle-aged A53T-SNCA mice, recorded in vivo. J, Frequency distribution map. The in vivo firing frequency of each r-VTA DA neuron is color coded (legend gives the frequency range) in the control and A53T-SNCA mice, respectively. Line in the scatter dot-plot represents the median. $\mathrm{ns}, p>0.05$, Mann-Whitney test. 
A

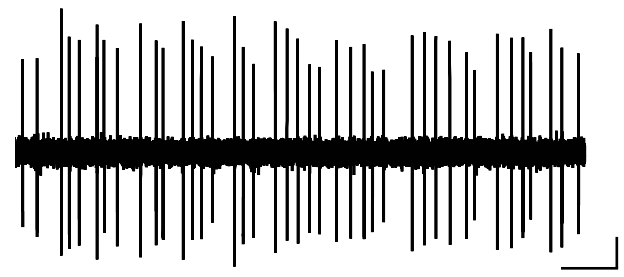

| | || |||||| || || ||| | || || || || || || || | | || ||

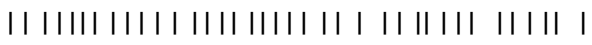

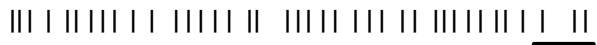

B

\section{A53T-SNCA}

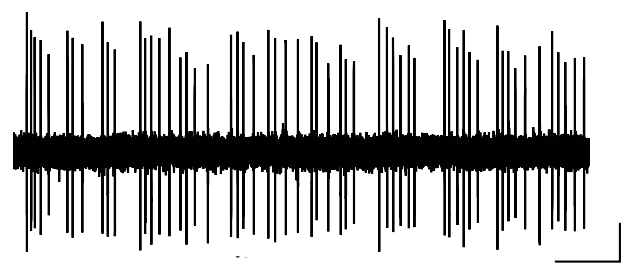

| ||||||| || | ||||| |||| |||| ||||| ||||||| | | ||||| | ||| |||||| | ||| ||

| || || | | | |||||||| | |||| |||||||| |||||||| |||| ||||| |||| || || || || ||

|||I| | ||| | |||||| ||||||||| ||||||| ||||||||| |||||| | | |||||| | ||| ||| |||
C
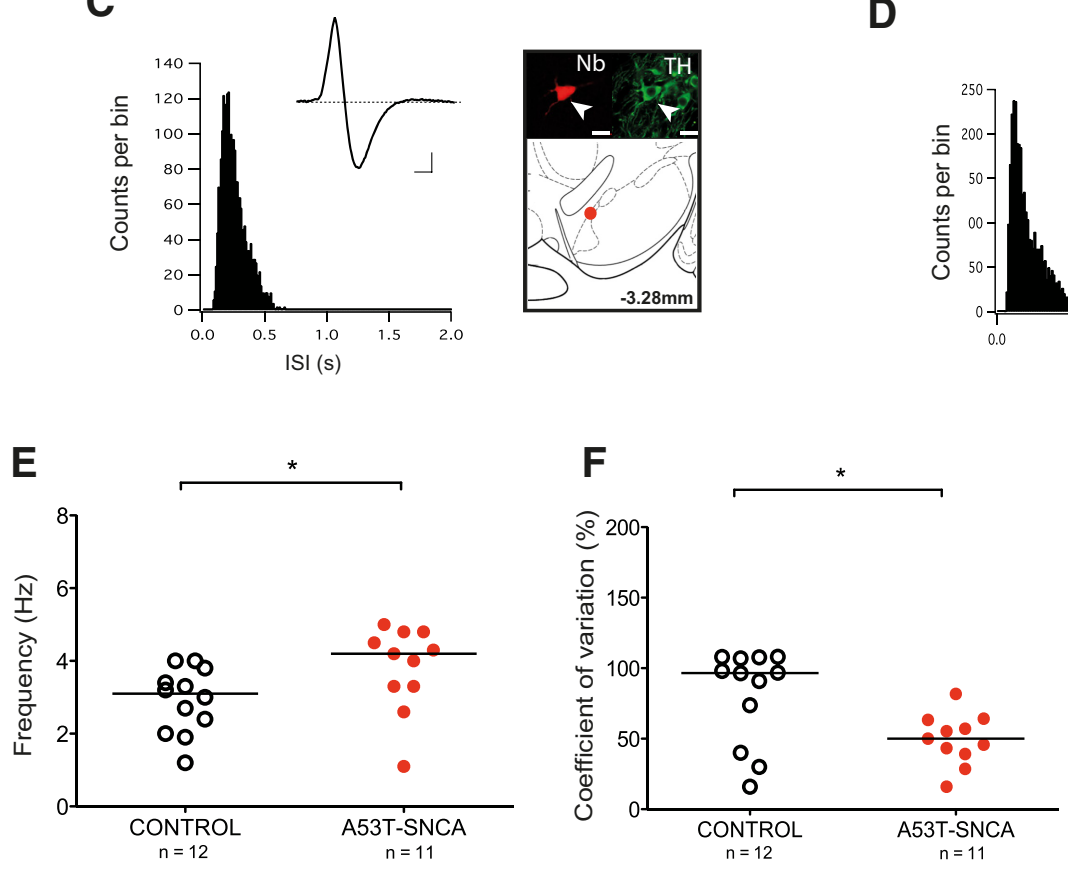

D
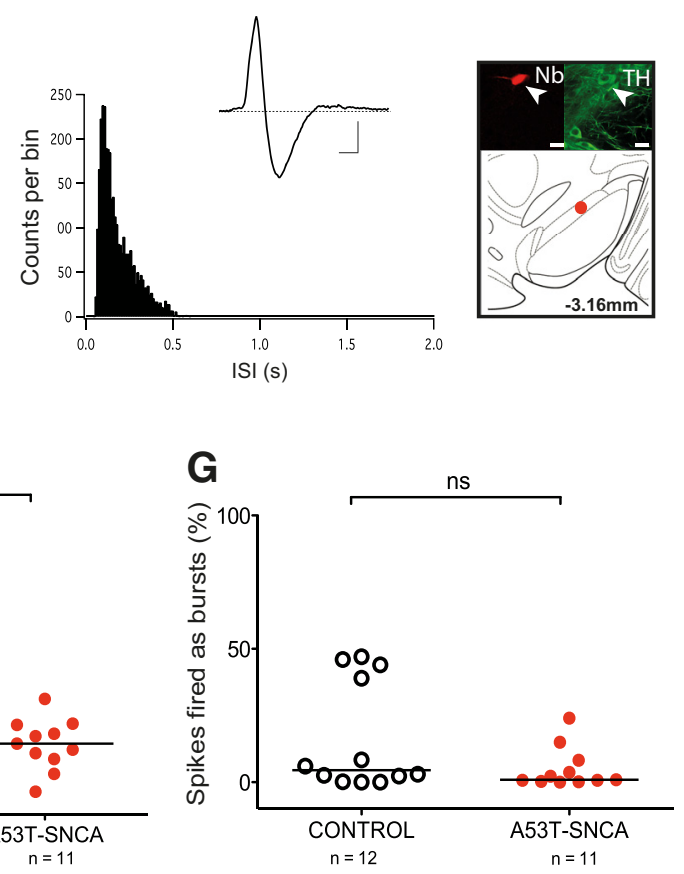

H

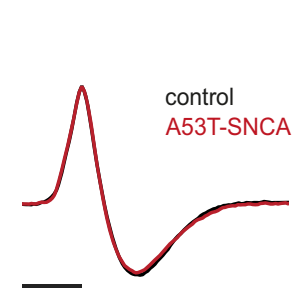

I

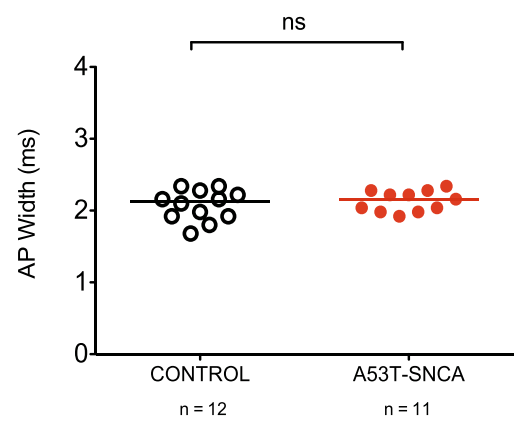

J

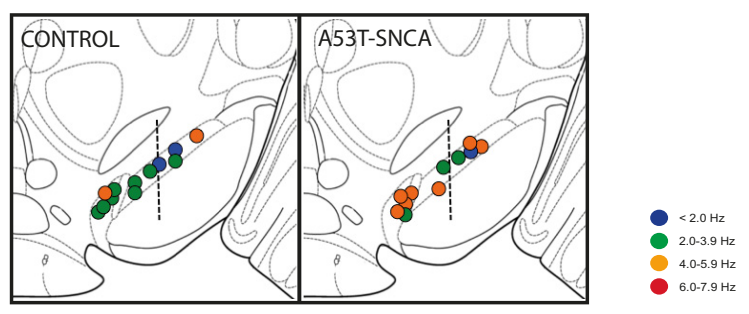

Figure 4. Mild in vivo firing phenotype in young adult DA SN neurons of A53T-SNCA mice. I, Spontaneous extracellular in vivo single unit activity of identified DA SN neurons in the 3 months old mice, shown as 10 s original trace, in control $(\boldsymbol{A})$, and young A53T-SNCA (B), respectively (Scale bar, $0.2 \mathrm{mV}, 1 \mathrm{~s})$, with corresponding $30 \mathrm{~s}$ raster plot at the bottom. Scale bar, $1 \mathrm{~s}$. C, $\boldsymbol{D}$, ISIH depicting the pattern of firing in the DA SN neurons in the control (C) and young A53T-SNCA mice (D) with respective averaged biphasic waveform (inset). Scale bar, $0.2 \mathrm{mV}, 1 \mathrm{~ms}$. (LSM of respective juxtacellularly labeled single DA SN neuron along with multilabeling immunocytochemistry (bottom). The Nb-filled neurons (red) expressed TH (green) and were located in the SN. Scale bar, $20 \mu \mathrm{m}$. Right, Map showing the location of juxtacellularly labeled single recorded DASN neuron (bregma -3.08 and $-3.28 \mathrm{~mm}$, respectively). $E, G$, In vivo firing frequency of the DA SN neurons in the young A53T-SNCA mice is significantly increased $(\boldsymbol{E})$. There is a significant decrease in the $\mathrm{VV}$ in the young A53T-SNCA mice $(\boldsymbol{F})$ and the SFB is not changed $(\boldsymbol{G})$. $\boldsymbol{H}, 0$ verlaid plot of mean averaged action potential waveforms (normalized to 1) of DA SN neurons from young adult A53T-SNCA mice (red) and age-matched controls (black) recorded in vivo. Scale bar, $1 \mathrm{~s}$. I, AP duration of DA SN neurons in controls and young adult A53T-SNCA mice, recorded in vivo.J, Frequency distribution map. The in vivo firing frequency of each DA SN neuron is color-coded (legend gives the frequency range) in the control and young A53T-SNCA mice, respectively. Line in the scatter dot-plot represents the median; ${ }^{*} p<0.05 ; n s, p>0.05$, Mann-Whitney test. 
A

control

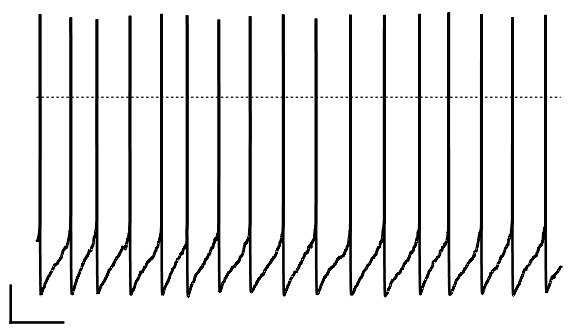

C control $+1 \mu \mathrm{M}$ phrixotoxin-2

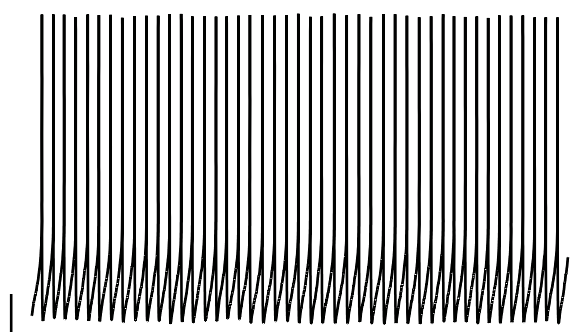

B

A53T-SNCA

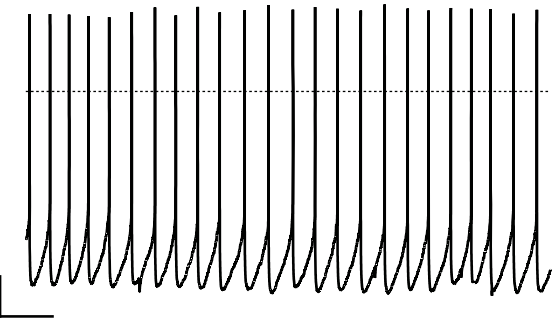

D A53T-SNCA + $1 \mu \mathrm{M}$ phrixotoxin-2

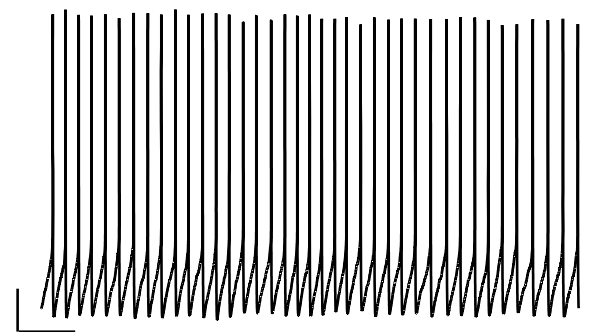

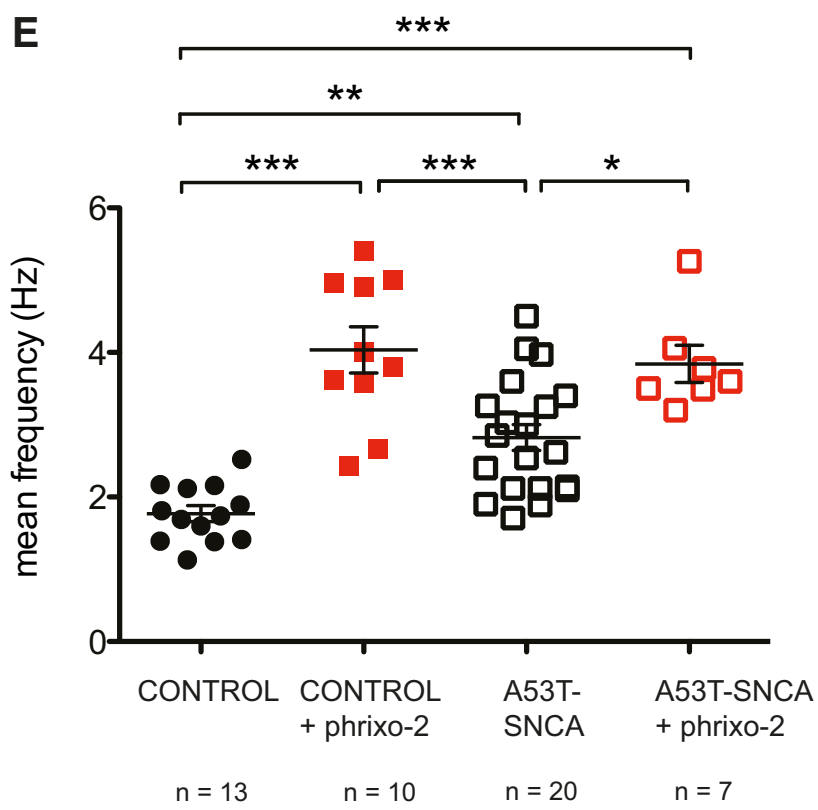

Figure 5. Increased firing frequencies of DA SN neurons in A53T-SNCA mice are preserved in vitro and occluded by phrixotoxin-2. $A, B$, Current-clamp traces of whole-cell patch-clamp recordings showing the spontaneous in vitro activity of DA SN neurons in control ( $\boldsymbol{A}$ ) and A53T-SNCA mice ( $\boldsymbol{B})$. Scale bars, $1 \mathrm{s,}, 10 \mathrm{mV}$. C, $\boldsymbol{D}$, Current-clamp traces of whole-cell patch-clamp recordings showing the spontaneous in vitro activity of DA SN neurons in control ( $($ ) and A53T-SNCA mice (D) in the presence of $1 \mu \mathrm{M}$ phrixotoxin-2. Scale bars, $1 \mathrm{~s}, 10 \mathrm{mV}$. $E$, Mean firing frequencies of DA SN neurons (mean \pm SEM) in control and A53T-SNCA mice under control conditions and in the presence of $1 \mu \mathrm{M}$ phrixotoxin-2. Note the absence of a significant difference between frequencies in controls and A53T-SNCA in $1 \mu \mathrm{M}$ phrixotoxin-2. One-way ANOVA with Tukey's multiple-comparison test; ${ }^{* * *} p<0.0005,{ }^{* *} p<0.005,{ }^{*} p<0.05$.

al., 2008). As shown in Figure $3 A, D$, middle-aged DA VTA neurons from A53T-SNCA and control mice did not display any differences in their mean in vivo firing frequencies (Fig. $3 E$; controls: $2.5 \pm 0.3 \mathrm{~Hz}, n=10, N=4$; A53T-SNCA: $2.4 \pm 0.3 \mathrm{~Hz}, n=$ $10, N=3, p=0.85$, Mann-Whitney test). In addition, we also found no genotype differences in the regularity of discharge $(\mathrm{CV})$ and burstiness in these DA VTA neurons (Fig. 3F; CV, controls: $66 \pm 11 \%, n=10, N=4$; A53T-SNCA: $65 \pm 16 \%, n=10, N=$ $3, p=0.74$, Mann-Whitney test; Fig. 3G; SFB, controls: $6 \pm 3 \%$, $n=10, N=4$; A53T-SNCA: $16 \pm 9 \%, n=10, N=3, p=0.70$,
Mann-Whitney test; Fig. 3J, shows the frequency distribution map). Finally, also no genotype related changes in in vivo AP waveforms were detected in identified DA VTA neurons (Fig. $3 H, I$; mean AP width, ms; VTA DA neurons, control: $2.2 \pm 0.08$, $n=10, N=4$; A53T-SNCA: $2.1 \pm 0.1, n=10, N=3, p=0.1712$, Mann-Whitney $U$ ).

Thus, our data show that DA SN neurons from middle-aged mice are selectively affected by mutant $\alpha$-synuclein expression.

Next, we investigated the age-dependency of this phenotype in DA SN neurons by comparing electrical in vivo activity of DA 
A

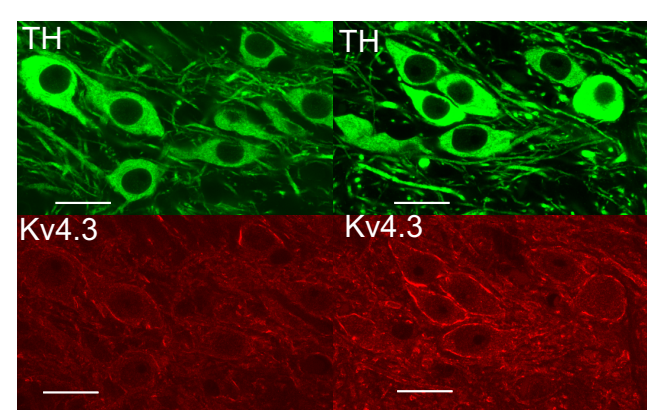

C

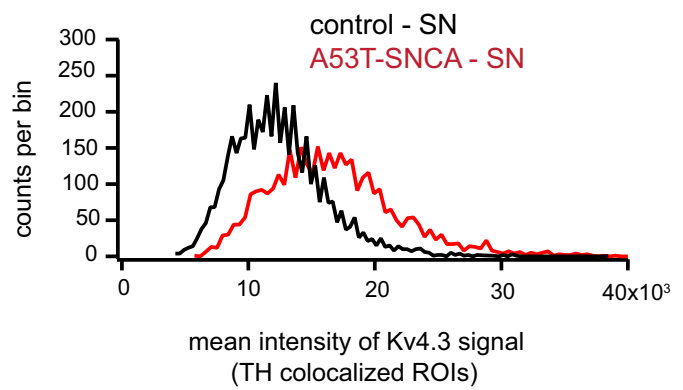

$\mathbf{E}$

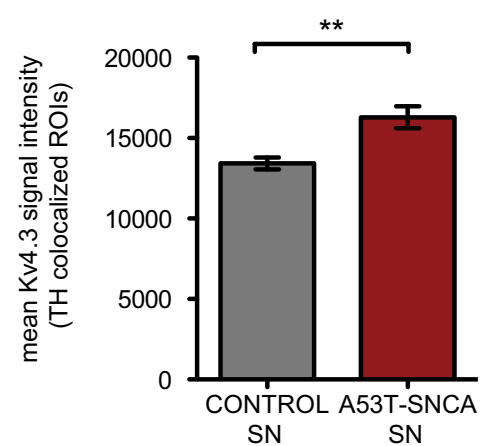

\section{B control-VTA A53T-SNCA-VTA}

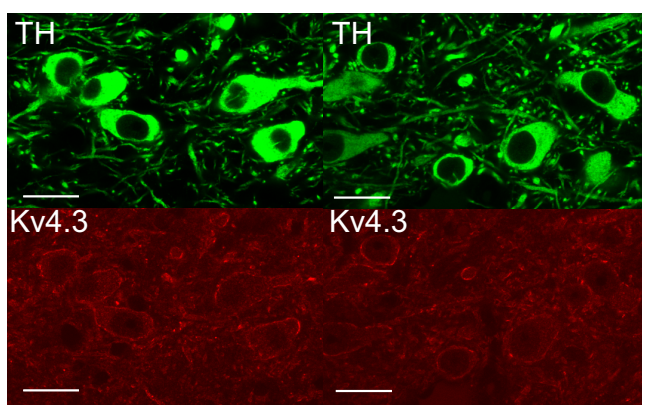

D

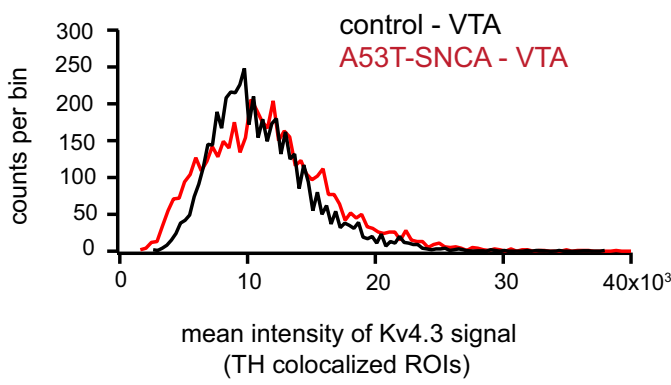

$\mathbf{F}$

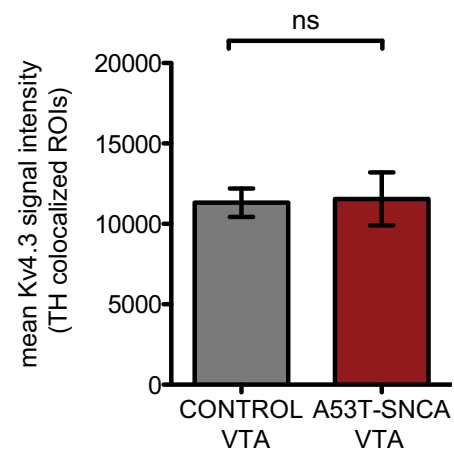

Figure 6. Selective increase of Kv4.3 protein expression in DA SN neurons of A53T-SNCA mice. $A, B$, Confocal images of immunocytochemistry of DA SN and DA VTA neurons for TH (green, top) and Kv4.3 channel protein (red, bottom) in control ( $\boldsymbol{A}$ ) and A53T-SNCA (B) mice, respectively. Scale bar, $20 \mu \mathrm{m}$. $\boldsymbol{C}, \boldsymbol{D}$, Histogram showing intensity of Kv4.3 immunosignals for TH-positive R0ls, in DA SN ( $\boldsymbol{C}$ ) and DA VTA (D) neurons in control (black) and A53T-SNCA (red) mice, respectively. $\boldsymbol{E}$, $\boldsymbol{F}$, Comparison of mean TH-colocalized Kv4.3 immunosignals from DA SN (E) and DA VTA $(\boldsymbol{F})$ neurons in control and A53T-SNCA mice; ${ }^{* *} p>0.005 ;$ ns, Mann-Whitney test.

SN neurons in young adult (3- to 4-months-old) A53T-SNCA and age-matched control mice. As we show in Figure 4, labeled and identified DA SN neurons from young adult A53T-SNCA mice already displayed significantly faster in vivo firing frequencies compared with age-matched controls. However, their mean firing frequencies were only $\sim 50 \%$ higher compared with agematched controls and there was still considerable overlap in the firing ranges of A53T-SNCA and control DA SN neurons (Fig. $4 E$; controls: $2.9 \pm 0.3 \mathrm{~Hz}, n=12, N=3$; A53T-SNCA: $3.9 \pm 0.4$ $\mathrm{Hz}, n=11, N=3, p=0.03$, Mann-Whitney test). Also, genotype-dependent differences in action potential repolarization were not yet apparent compared with middle age (Fig. 4 H, I; mean AP width, ms; control: $2.1 \pm 0.06, n=12, N=3$; A53TSNCA, $2.1 \pm 0.04, n=11, N=3 ; p=0.57$, Mann-Whitney $U$ ). The regularity of firing (CV) was significantly lower in 3-monthold DA SN neurons from A53T-SNCA mice compared with controls (Fig. 4F; CV, controls: $81 \pm 10 \%, n=12, N=3$; A53TSNCA: $50 \pm 5 \%, n=11, N=3, p=0.02$, Mann-Whitney test). However, similar to the dataset from middle-aged mice, we found no significant genotype effect on the burstiness (Fig. $4 G$; SFB, controls: $17 \pm 6 \%, n=12, N=3$; A53T-SNCA: $5 \pm 2 \%, n=$ $11, N=3, p=0.28$, Mann-Whitney test; Fig. $4 J$, shows the frequency distribution map). The comparison of young adult and middle-aged mice revealed that the selective enhancement of mean firing frequencies in DA SN neurons began to emerge in young adult animals.

In summary, we have identified a selective and progressive in vivo phenotype of vulnerable DA SN neurons in response to a gain-of-function mutant $\alpha$-synuclein. Middle-aged A53T-SNCA DA SN neurons showed an $\sim 100 \%$ increase in their in vivo mean firing rates compared with controls. In addition, action potential repolarization was prolonged in middle-aged A53T-SNCA DA SN neurons. Although pacemaking patterns were more prominent, other parameters of firing, regularity and burstiness, were not affected. We also show that this increased firing rate in DA neurons was selective for those in the $\mathrm{SN}$ and was not observed in the more resistant neighboring VTA DA neurons. 
A

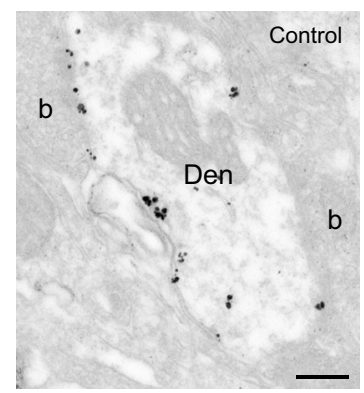

B
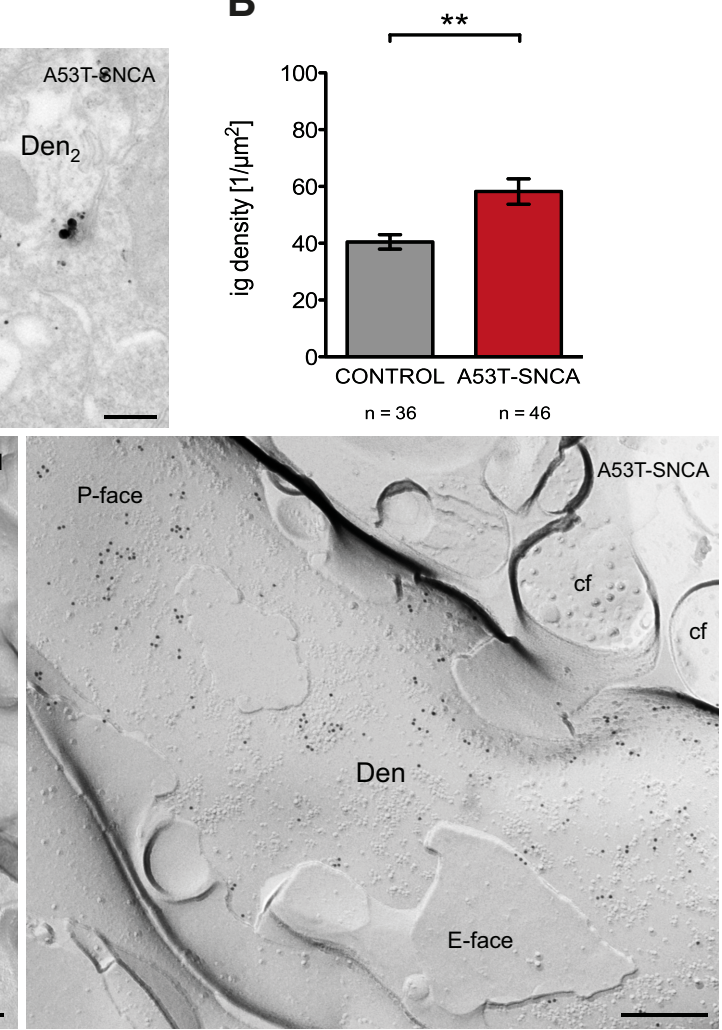

Figure 7. Increased Kv4.3 channel expression in the plasma membrane of DA SN neurons in A53T-SNCA mice. $\boldsymbol{A}$, Electron micrographs showing immunoreactivity for Kv4.3 in the SN. Preembedding (top) and SDS-FRL replica (bottom) immunoelectron microscopy demonstrate that the Kv4.3 proteins (IG particles) are distributed in a clustered fashion along the extrasynaptic plasma membrane of dendritic shafts (Den) of putative dopaminergic cells on tissues obtained from control (control; top and bottom left; $n=36$ dendrites) and transgenic (A53T-SNCA; top and bottom right; $n=46$ dendrites) mice. Both immunocytochemical methods revealed higher surface expression of the channel subunit in transgenic animals than in control animals. $B$, This was further validated by quantification of IG density for Kv4.3 on replicas, which was significantly lower in neurons from WT compared with cells from A53T-SNCA mice $\left(t\right.$ test; $\left.{ }^{* *} p=0.0045,{ }^{*} p=0.0142\right)$. P-face, Protoplasmic face; E-face, exoplasmic face; b, bouton; cf, cross-fractured. Scale bars, $0.2 \mu \mathrm{m}$.

\section{Increased firing frequencies of DA SN neurons in A53T- SNCA mice are partially preserved in vitro and are occluded by pharmacological inhibition of Kv4.3 channels}

To define the underlying biophysical mechanisms of increased firing of DA SN neurons in A53T-SNCA mice, we recorded from synaptically isolated DA SN neurons in in vitro brain slices from middle-aged A53T-SNCA and age-matched control mice. Similar to in vivo, we observed significantly higher firing frequencies in DA SN neurons of A53T-SNCA compared with controls (Fig. $5 A, B, E$; control: $1.8 \pm 0.1 \mathrm{~Hz}, n=13, N=4$; A53T-SNCA: $2.8 \pm$ $0.2 \mathrm{~Hz}, n=20, N=5, p<0.0001$, one-way ANOVA, Tukey's multiple-comparison test). The in vitro firing frequency in DA SN neurons was $\sim 55 \%$ higher compared with controls, whereas in vivo we detected an $\sim 90 \%$ frequency increase (Fig. 2). This difference in effect indicates that at least $60 \%$ of the mutant $\alpha$-synuclein-induced firing phenotype of DA SN neurons was mediated by intrinsic changes of the cell-autonomous firing rates.

The in vitro data suggested altered pacemaker currents in DA SN neurons, prominently among them HCN channels (Neuhoff et al., 2002) and Kv4.3/Kchip3a-mediated A-type potassium channels (Liss et al., 2001; Khaliq and Bean, 2008; Amendola et al., 2012). While HCN channel-mediated sag amplitudes were not different in A53T-SNCA and controls (data not shown), selective pharmacological inhibition of A-type Kv4 potassium channels with $1 \mu \mathrm{M}$ phrixotoxin-2 (Diochot et al., 1999) entirely occluded the frequency differences between the two genotypes
(Fig. 5C, D, E; control + phrixotoxin-2: $4.0 \pm 0.3 \mathrm{~Hz}, n=10, N=$ 3; A53T-SNCA + phrixotoxin-2: $3.8 \pm 0.3 \mathrm{~Hz}, n=7, N=3, p<$ 0.0001, one-way ANOVA, Tukey's multiple-comparison test). These results suggest reduced A-type Kv4.3 channel expression or function in DA SN neurons of A53T-SNCA mice. In contrast to the frequency effect, the prolonged action potential repolarization of A53T-SNCA DA SN neurons, which was also preserved in vitro, was not occluded by phrixotoxin- 2 and thus mediated by different mechanisms (data not shown).

\section{A-type K channel dysfunction in DA SN neurons in A53T- SNCA is not mediated by reduced $\mathrm{Kv} 4.3$ protein expression} Our in vitro experiments identified reduced Kv4.3 channel function to be responsible for the enhanced frequency phenotype of DA SN neurons from middle-aged A53T-SNCA mice. As one simple explanation might be a mutant $\alpha$-synuclein-induced reduction of $\mathrm{Kv} 4.3$ subunit expression, we performed Kv4.3 immunohistochemistry and confocal imaging in middle-aged A53T-SNCA and age-matched control mice. In accordance with previous studies (Liss et al., 2001) Kv4.3 immunoreactivity is present in DA SN and DA VTA neurons (Fig. 6A,B). As shown in Figure $6 A$, we did not observe any decrease of Kv4.3 immunosignal in DA SN neurons from A53T-SNCA mice compared with controls but rather an increase. In contrast, this increase was not observed in DA VTA neurons from A53T-SNCA mice (Fig. 6B). Figure $6 C, D$, plot the density distributions of mean $\mathrm{Kv} 4.3 \mathrm{immu}-$ nosignals in TH-positive regions of interests for SN and VTA. It is 
A

control

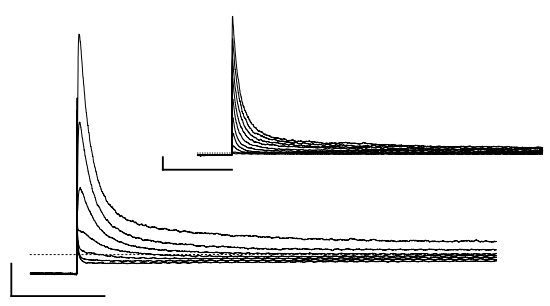

D

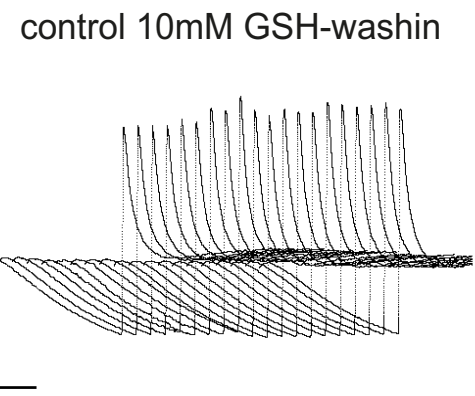

B

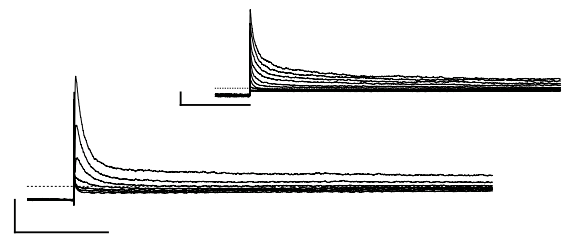

E

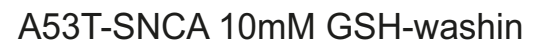

C

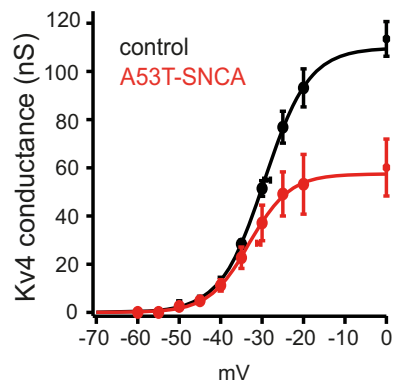

F

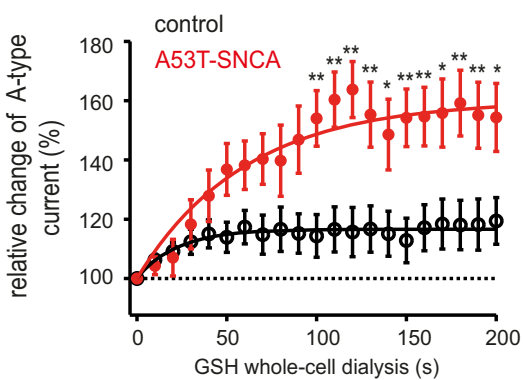

H

A53T-SNCA GSH-washin
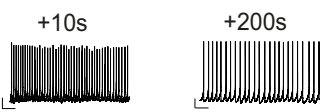

control

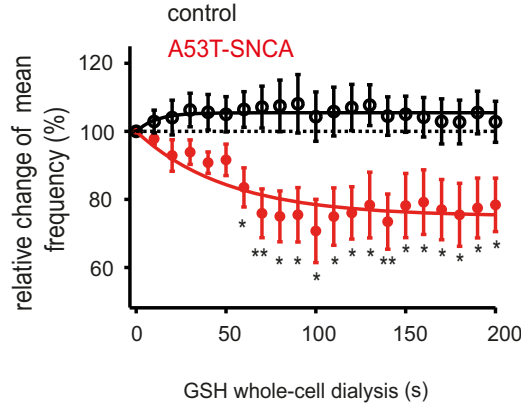

Figure 8. DA SN neurons in A53T-SNCA mice display reduced A-type potassium currents and glutathione-mediated rescue of A-type currents. $A, B$, Voltage-clamp traces of whole-cell (swc) and nucleated outside-out (nuo, insets) recordings of DA SN neurons in control $(\boldsymbol{A})$ and A53-SNCA mice $(\boldsymbol{B})$, showing fast inactivating potassium channel currents in response to depolarizing voltage steps (increments swc: $5 \mathrm{mV}$; nucleated $10 \mathrm{mV}$ ) from a prepotential of $-100 \mathrm{mV}$. Scale bars: swc, $200 \mathrm{~ms}, 500 \mathrm{pA}$; nuo, $200 \mathrm{~ms}, 300 \mathrm{pA}$. C, Mean steady-state activation of A-type (Kv4.3) potassium conductances (mean \pm SEM) recorded in standard whole-cell in DA SN neurons of wild-type and A53T-SNCA mice. Lines in $\boldsymbol{C}$ and $\boldsymbol{E}$ represent fits of the mean data with Boltzmann equations. $\boldsymbol{D}, \boldsymbol{E}$ Voltage-clamp traces of whole-cell patch-clamp recordings showing the in vitro dialysis of $10 \mathrm{~mm}$ GSH on DA SN neurons in control (D) and A53T-SNCA mice (E). Scale bars, $400 \mathrm{pA}, 200 \mathrm{~ms}$. $\boldsymbol{F}$, Graph showing the relative change of A-type potassium current (mean \pm SEM) upon GSH dialysis on DA SN neurons from control (black) and A53T-SNCA (red) mice, respectively. The black and red lines represent exponential fits of mean control and A53T data, respectively. G, Mean Kv 4 conductances (mean \pm SEM, ns) in DA SN neurons of control and A53T-SNCA mice and the Kv4 conductance after GSH dialysis. Note the significant decrease of Kv4 conductance in the DA SN neurons of the A53T-SNCA mice compared with controls and the significant increase of Kv4 conductances in A53T-SNCA after GSH dialysis compared with those in A53T-SNCA recorded under control conditions. H, Frequency changes in the DA SN neurons of control (black) and A53T-SNCA (red) mice in response to GSH dialysis. Current-clamp traces showing the spontaneous in vitro activity of DA SN neurons in A53T-SNCA mice after 10 and $200 \mathrm{~s}$ dialysis of GSH (top). Graph showing the relative changes in mean frequencies of DA SN neurons in control (black) and A53T-SNCA mice (red), respectively, during GSH dialysis (bottom). Note the significant decrease of mean frequency during GSH dialysis in DA SN neurons of A53T-SNCA mice, compared with controls. The black and red lines represent exponential fits of mean control and A53T data, respectively. Mann-Whitney test; ${ }^{* * *} p<0.0005,{ }^{* *} p<$ $0.005,{ }^{*} p<0.05$.

apparent that the Kv4.3 immunosignal density distribution is shifted to higher intensities in DA SN neurons from A53T-SNCA mice (Fig. 6C), whereas it is not affected by genotype in DA VTA neurons (Fig. $6 D$ ). This rightward shift resulted in an $\sim 20 \%$ significant increase of mean Kv4.3 signal intensity in DA SN neu- rons from A53T-SCNA mice compared with controls (Fig. 6C,E; control: $13422 \pm 368, n=4833 \mathrm{TH}^{+}$-ROIs; A53T-SNCA: $16,289 \pm 885, n=3670 \mathrm{TH}^{+}$-ROIs, $p=0.0052$, Mann-Whitney test) compared with no difference in the VTA (Fig. $6 D$, F; control: $11,320 \pm 368, n=5017 \mathrm{TH}^{+}$-ROIs; A53T-SNCA: 11,550 \pm 
Table 1. Gating parameters of Kv4 channels

\begin{tabular}{lccc}
\hline Standard whole-cell & WT $(n=9)$ & A53T $(n=8)$ & $p$ \\
\hline Steady-state activation Kv4 (mV) & & & \\
$\quad V_{50}$ & $-28.8 \pm 0.8$ & $-30.8 \pm 0.5$ & ns \\
$\quad$ Slope factor & $5.9 \pm 0.7$ & $6.0 \pm 0.2$ & $\mathrm{~ns}$ \\
Steady-state inactivation Kv4 (mV) & $(n=14)$ & $(n=11)$ & $\mathrm{ns}$ \\
V $_{50}$ & $-61.4 \pm 0.6$ & $-60.0 \pm 0.8$ & $\mathrm{~ns}$ \\
$\quad$ Slope factor & $5.3 \pm 0.3$ & $5.0 \pm 0.3$ & $\mathrm{~ns}$ \\
Nucleated outside-out & $(n=6)$ & $(n=4)$ & $\mathrm{ns}$ \\
\hline Tau-inactivation@-30 mV (ms) & $13.8 \pm 1.3$ & $13.1 \pm 0.9$ & $\mathrm{~ns}$ \\
Tau-recovery@-80 ms (ms) & $9.8 \pm 0.2$ & $10.9 \pm 0.9$ & $\mathrm{~ns}$ \\
\hline
\end{tabular}

1648, $n=4645 \mathrm{TH}^{+}$-ROIs, $p=0.84$, Mann-Whitney test). In addition, Kv4.3 signal intensities were independent of the sizes of $\mathrm{TH}$-positive region of interests in A53T-SNCA and controls (data not shown). In addition, we used immunogold labeling on freeze-fracture replicas of DA SN neuronal membranes to quantify Kv4.3 channel subunits in the plasma membrane. This is important as only Kv4.3 channels in the plasma membrane are functional and thus could be directly involved in frequency control. As shown in Figure 7, we again found no evidence for a decrease of Kv4.3 subunits residing in dendritic plasma membranes of DA SN neurons from A53T-SNCA mice but again a mild but significant increase $(\sim 30 \%)$ of the density of immunogold (IG) labels in the dendritic plasma membranes of A53T DA SN neurons compared with controls (Fig. $7 B$; control: $41 \pm 3$, $n=36, N=3$; A53T-SNCA: $58 \pm 5, n=46, N=3$ ). In summary, these data give no evidence for a reduced expression or membrane targeting of Kv4.3 proteins in SN DA neurons from A53TSNCA mice. Thus, functional impairments of Kv4.3 channels are likely to be responsible for the observed enhanced firing phenotype.

\section{A-type K channel dysfunction is rescued by intracellular dialysis of glutathione}

As we found no evidence for reduced Kv4.3 channel expression or membrane targeting, we reasoned that a functional impairment of Kv4.3 channels present in the membrane was more likely. As shown in Figure $8 A, C$, we directly studied A-type Kv4.3 current amplitudes and gating parameters in standard-whole-cell and also, for improved space-clamp condition, in nucleated outsideout recordings. Both configurations revealed an $\sim 40 \%$ reduction of maximal A-type Kv4.3 potassium conductances in DA SN neurons of A53T-SNCA mice compared with controls (Kv4.3 max conductances in standard whole-cell, see below; Fig. 8G; nucleated outside-out patches, control: $22.7 \pm 3.4 \mathrm{nS}, n=6$; A53TSNCA: $13.1 \pm 2.1 \mathrm{nS}, n=4$; unpaired $t$ test, $p=0.01$ ).

In contrast, we found no major differences in voltagedependent steady-state gating parameters (as recorded in the standard whole-cell configuration) or inactivation and recovery kinetics (these fast time constant were determined from nucleated outside-out recordings for improved space-clamp conditions; Table 1). Next, we tested whether smaller A-type Kv4 whole-cell current amplitudes in DA SN neurons from A53TSCNA mice could be recovered. As we had previously noted the redox-sensitivity of A-type channels in DA SN neurons (Roeper and Ashcroft, 1994) and the redox-regulation of Kv4 channels in general has been studied in great detail (Wang et al., 2005, 2007; Wang and Covarrubias, 2006), we tested whether oxidative modification was responsible for the smaller $\mathrm{Kv} 4$ current amplitudes in DA SN neurons from middle-aged A53T-SNCA mice compared with controls. Figure $8 D-F$, shows that intracellular dialy- sis of the physiological reducing agent glutathione (GSH, $10 \mathrm{~mm}$ ) had only small effects on A-type K currents in whole-cell patchclamp recordings from WT DA SN neurons, but lead to a large increase in current amplitudes in A53T DA SN neurons. This GSH-mediated rescue of A-type currents was selective: neither holding currents, HCN channel-mediated inward currents nor non-inactivating outward currents were affected in DA SN neurons. Figure $8 F$, displays the mean data showing that intracellular GSH-dialysis induced a significant and stable increase of A-type current amplitudes of $\sim 60 \%$ in A53T-SNCA DA SN neurons. This redox-mediated rescue of $\mathrm{Kv} 4$ current amplitudes was approximately five times larger compared with the small increase observed in DA SN neurons from control mice. Figure $8 G$, displays the maximal Kv4.3 conductances of the two genotypes under standard recording conditions as well as during prolonged dialysis with $10 \mathrm{~mm}$ GSH. It highlights our two key findings, a significant reduction of the mean maximal Kv4.3 conductance in A53T-SNCA compared with control (control \pm SEM: $114 \pm 7.2$ $\mathrm{nS}, n=8, N=4$; A53T-SNCA \pm SEM: $70 \pm 12 \mathrm{nS}, n=9, N=5$, $p=0.0014$, one-way ANOVA, Tukey's multiple-comparison test) and the significant GSH-induced increase of mean maximal Kv4.3 conductances observed in A53T-SNCA but absent in control (control \pm SEM: $96 \pm 11.5 \mathrm{nS}, n=8, N=4$; A53TSNCA \pm SEM: $129 \pm 9.2 \mathrm{nS}, n=14, N=6, p=0.0014$, one-way ANOVA, Tukey's multiple-comparison test). Finally, we tested whether glutathione-recovered Kv4.3 channels contribute to pacemaker function. Figure $8 \mathrm{H}$, shows the spontaneous frequency change recorded in current-clamp during dialysis of 10 $\mathrm{mm}$ GSH. Whereas the frequency of DA SN neurons from controls was not affected during GSH dialysis, the frequency of DA SN neurons from A53T-SNCA was significantly reduced $(\sim 25 \%$; relative change of mean frequency: control \pm SEM: $105 \pm 5.2 \%$, $n=8, N=3$; A53T-SNCA \pm SEM: $83 \pm 5.2, n=5, N=3, p=$ 0.01 , Mann-Whitney test). These results confirm the notion that the redox-mediated recovery of Kv4.3 channels is functionally relevant in reducing firing rates in DA SN neurons from A53TSNCA mice. These data demonstrate that mutant a-synuclein induces oxidative dysfunction of Kv4.3 channels complexes in DA SN neurons resulting in enhanced in vitro pacemaker frequencies. These intrinsic changes of DA SN neurons are likely to contribute to their enhanced in vivo firing in middle-aged A53TSNCA mice.

\section{Discussion}

We identified a glutathione-sensitive dysfunction of A-type Kv4.3 channels as the causal mechanism for the $~ 55 \%$ enhanced intrinsic in vitro firing rates of DA SN neurons from middle-aged A53T-SNCA mice. This mutant $\alpha$-synuclein-induced acceleration of intrinsic firing rates is also likely to be the dominant mechanism for the $\sim 90 \%$ increase of in vivo firing rates of DA SN neurons from middle-aged A53T-SNCA mice. The larger acceleration of in vivo firing rates compared with those detected in vitro indicates that additional non-cell autonomous mechanisms, such as an altered excitation/inhibition balance, contribute to the enhanced firing phenotype in vivo. In addition, the altered action potential repolarization observed in middle-aged A53T-SNCA mice was independent of Kv4.3 channel function. Importantly, the enhanced firing phenotype was selective for middle-aged DA SN neurons in the A53T-SNCA model and not observed in agematched VTA DA neurons, although they express similar levels of mutant $\alpha$-synuclein. Thus, the firing frequency enhancement of DA SN neurons might constitute one of the first acquired pathophysiological stages of the dopamine system in PD, thereby 
enhancing the constitutive differences in vulnerability between DA subpopulations (i.e., stressful pacemaker theory) even before the onset of neurodegeneration itself. In vivo, the effect of reduced $\mathrm{Kv} 4$ channel function might be further potentiated by their important role in dendritic synaptic integration, in particular dampening excitatory synaptic inputs and dendritic action potential backpropagation (Johnston et al., 2000; Gentet and Williams, 2007). Moreover, the enhanced in vivo firing of DA SN neurons constitutes a much earlier and more pronounced response to mutant $\alpha$-synuclein compared with the late onset of only subtle changes in axonal DA release in the same A53T-SNCA mouse model (>18 months; Burré et al., 2012; Platt et al., 2012).

The progressive in vivo enhancement of firing rates and delayed action potential repolarization might not only be a functional response of DA SN neurons to mutant $\alpha$-synuclein, but could itself contribute to disease progression by enhancing constitutive differences in activity-dependent calcium and oxidative loading between DA subpopulations (Surmeier and Schumacker, 2013). This positive feedforward loop accelerating the stressful pacemaker could constitute an acquired component of selective vulnerability of DA SN neurons and this putative sensitization process might be a novel target for early neuroprotective therapy (Surmeier and Schumacker, 2013). Although the mechanisms linking mutant $\alpha$-synuclein to Kv4.3 channel dysfunction remain to be defined, we recently demonstrated that proteasomal dysfunction itself, one of the downstream effects of mutant $\alpha$-synuclein, induces a similar DA SN selective enhancement of in vivo firing rates (Subramaniam et al., 2014). A recent elegant model overexpressing human $\alpha$-synuclein in a $\alpha$-synuclein knock-out background reported reduced in vivo firing rates and increased firing variability of DA SN neurons in old mice (18-22 month) combined with an early onset defect in striatal dopamine release (Janezic et al., 2013). However, this study did not investigate whether the in vivo firing changes were selective to SN DA neurons or whether the in vitro pacemaker function of DA SN neurons was affected. Thus, it will also be important to define whether overexpression of wild-type $\alpha$-synuclein will induce a similar acceleration of cell-autonomous pacemaker firing mediated by Kv4.3 dysfunction in middle-aged DA SN neurons and if so, whether this phenotype changes in old age or after onset of DA neurodegeneration.

Although our study does not define the exact mechanism of mutant $\alpha$-synuclein-induced oxidative dysfunction of $\mathrm{Kv} 4.3$ channels in DA SN neurons, recombinant studies strongly suggest the possibility of a direct and reversible oxidative modification of the T1-assembly domain-associated redox switch in the Kv4 $\alpha$-subunit (Wang et al., 2005, 2007; Wang and Covarrubias, 2006). Detailed proteomic studies of native Kv4 channel complexes (Amarillo et al., 2008; Covarrubias et al., 2008) in DA SN neurons are needed to define both the site and type of oxidative channel modifications. Our findings highlight the relevance of redox control in DA SN neurons and are in line with recent studies on inducible pluripotent stem cells-derived neurons, where A53T-SNCA was found to induce nitrosative stress in both human DA SN-like and cortical neurons (Topf et al., 2003; Fitch et al., 2006). Regardless of the detailed biochemical mechanisms, the accelerated firing phenotype of DA SN neurons preceding release dysfunction and degeneration constitutes an early biomarker of the dopamine system at risk in PD.

\section{References}

Amarillo Y, De Santiago-Castillo JA, Dougherty K, Maffie J, Kwon E, Covarrubias M, Rudy B (2008) Ternary Kv4.2 channels recapitulate voltage- dependent inactivation kinetics of A-type $\mathrm{K}+$ channels in cerebellar granule neurons. J Physiol 586:2093-2106. CrossRef Medline

Amendola J, Woodhouse A, Martin-Eauclaire MF, Goaillard JM (2012) $\mathrm{Ca}(2)(+) /$ cAMP-sensitive covariation of $\mathrm{I}(\mathrm{A})$ and $\mathrm{I}(\mathrm{H})$ voltage dependences tunes rebound firing in dopaminergic neurons. J Neurosci 32: 2166-2181. CrossRef Medline

Bingmer M, Schiemann J, Roeper J, Schneider G (2011) Measuring burstiness and regularity in oscillatory spike trains. J Neurosci Methods 201: 426-437. CrossRef Medline

Burré J, Sharma M, Südhof TC (2012) Systematic mutagenesis of alphasynuclein reveals distinct sequence requirements for physiological and pathological activities. J Neurosci 32:15227-15242. CrossRef Medline

Calì T, Ottolini D, Negro A, Brini M (2012) $\alpha$-Synuclein controls mitochondrial calcium homeostasis by enhancing endoplasmic reticulummitochondria interactions. J Biol Chem 287:17914-17929. CrossRef Medline

Chan CS, Gertler TS, Surmeier DJ (2009) Calcium homeostasis, selective vulnerability and Parkinson's disease. Trends Neurosci 32:249-256. CrossRef Medline

Covarrubias M, Bhattacharji A, De Santiago-Castillo JA, Dougherty K, Kaulin YA, Na-Phuket TR, Wang G (2008) The neuronal Kv4 channel complex. Neurochem Res 33:1558-1567. CrossRef Medline

Damier P, Hirsch EC, Agid Y, Graybiel AM (1999) The substantia nigra of the human brain: II. Patterns of loss of dopamine-containing neurons in Parkinson's disease. Brain 122:1437-1448. CrossRef Medline

Diochot S, Drici MD, Moinier D, Fink M, Lazdunski M (1999) Effects of phrixotoxins on the Kv4 family of potassium channels and implications for the role of Ito1 in cardiac electrogenesis. Br J Pharmacol 126:251-263. CrossRef Medline

Fearnley JM, Lees AJ (1991) Ageing and Parkinson's disease: substantia nigra regional selectivity. Brain 114:2283-2301. CrossRef Medline

Fitch TE, Sahr RN, Eastwood BJ, Zhou FC, Yang CR (2006) Dopamine D1/5 receptor modulation of firing rate and bidirectional theta burst firing in medial septal/vertical limb of diagonal band neurons in vivo. J Neurophysiol 95:2808-2820. CrossRef Medline

Franklin KB, Paxinos G (2008) The mouse brain in stereotaxic coordinates. San Diego: Academic.

Gan L, Vargas MR, Johnson DA, Johnson JA (2012) Astrocyte-specific overexpression of Nrf2 delays motor pathology and synuclein aggregation throughout the CNS in the alpha-synuclein mutant (A53T) mouse model. J Neurosci 32:17775-17787. CrossRef Medline

Gentet LJ, Williams SR (2007) Dopamine gates action potential backpropagation in midbrain dopaminergic neurons. J Neurosci 27:1892-1901. CrossRef Medline

Gispert S, Del Turco D, Garrett L, Chen A, Bernard DJ, Hamm-Clement J, Korf HW, Deller T, Braak H, Auburger G, Nussbaum RL (2003) Transgenic mice expressing mutant A53T human alpha-synuclein show neuronal dysfunction in the absence of aggregate formation. Mol Cell Neurosci 24:419-429. CrossRef Medline

Goedert M, Spillantini MG, Del Tredici K, Braak H (2013) 100 years of Lewy pathology. Nat Rev Neurol 9:13-24 CrossRef Medline

Grace AA, Bunney BS (1984) The control of firing pattern in nigral dopamine neurons: burst firing. J Neurosci 4:2877-2890. Medline

Gundersen HJ (1986) Stereology of arbitrary particles: a review of unbiased number and size estimators and the presentation of some new ones, in memory of William R. Thompson. J Microsc 143:3-45. CrossRef Medline

Hardy J (2010) Genetic analysis of pathways to Parkinson disease. Neuron 68:201-206. CrossRef Medline

Janezic S, Threlfell S, Dodson PD, Dowie MJ, Taylor TN, Potgieter D, Parkkinen L, Senior SL, Anwar S, Ryan B, Deltheil T, Kosillo P, Cioroch M, Wagner K, Ansorge O, Bannerman DM, Bolam JP, Magill PJ, Cragg SJ, Wade-Martins R (2013) Deficits in dopaminergic transmission precede neuron loss and dysfunction in a new Parkinson model. Proc Natl Acad Sci U S A 110:E4016-E4025. CrossRef Medline

Johnston D, Hoffman DA, Magee JC, Poolos NP, Watanabe S, Colbert CM, Migliore M (2000) Dendritic potassium channels in hippocampal pyramidal neurons. J Physiol 525:75-81. CrossRef Medline

Khaliq ZM, Bean BP (2008) Dynamic, nonlinear feedback regulation of slow pacemaking by A-type potassium current in ventral tegmental area neurons. J Neurosci 28:10905-10917. CrossRef Medline

Kulik A, Vida I, Fukazawa Y, Guetg N, Kasugai Y, Marker CL, Rigato F, Bettler B, Wickman K, Frotscher M, Shigemoto R (2006) Compartment- 
dependent colocalization of Kir3.2-containing $\mathrm{K}+$ channels and GABAB receptors in hippocampal pyramidal cells. J Neurosci 26:4289-4297. CrossRef Medline

Kurz A, Double KL, Lastres-Becker I, Tozzi A, Tantucci M, Bockhart V, Bonin M, García-Arencibia M, Nuber S, Schlaudraff F, Liss B, Fernández-Ruiz J, Gerlach M, Wüllner U, Lüddens H, Calabresi P, Auburger G, Gispert S (2010) A53T-alpha-synuclein overexpression impairs dopamine signaling and striatal synaptic plasticity in old mice. PLoS One 5:e11464. CrossRef Medline

Lammel S, Hetzel A, Häckel O, Jones I, Liss B, Roeper J (2008) Unique properties of mesoprefrontal neurons within a dual mesocorticolimbic dopamine system. Neuron 57:760-773. CrossRef Medline

Lees AJ, Hardy J, Revesz T (2009) Parkinson's disease. Lancet 373:20552066. CrossRef Medline

Liss B, Franz O, Sewing S, Bruns R, Neuhoff H, Roeper J (2001) Tuning pacemaker frequency of individual dopaminergic neurons by Kv4.3L and KChip3.1 transcription. EMBO J 20:5715-5724. CrossRef Medline

Liss B, Haeckel O, Wildmann J, Miki T, Seino S, Roeper J (2005) K-ATP channels promote the differential degeneration of dopaminergic midbrain neurons. Nat Neurosci 8:1742-1751. CrossRef Medline

Martin I, Dawson VL, Dawson TM (2011) Recent advances in the genetics of Parkinson's disease. Annu Rev Genomics Hum Genet 12:301-325. CrossRef Medline

Masugi-Tokita M, Tarusawa E, Watanabe M, Molnár E, Fujimoto K, Shigemoto R (2007) Number and density of AMPA receptors in individual synapses in the rat cerebellum as revealed by SDS-digested freeze-fracture replica labeling. J Neurosci 27:2135-2144. CrossRef 17314308

Neuhoff H, Neu A, Liss B, Roeper J (2002) I(h) channels contribute to the different functional properties of identified dopaminergic subpopulations in the midbrain. J Neurosci 22:1290-1302. Medline

Paumier KL, Sukoff Rizzo SJ, Berger Z, Chen Y, Gonzales C, Kaftan E, Li L, Lotarski S, Monaghan M, Shen W, Stolyar P, Vasilyev D, Zaleska MD, Hirst W (2013) Behavioral characterization of A53T mice reveals early and late stage deficits related to Parkinson's disease. PLoS One 8:e70274. CrossRef Medline

Pinault D (1996) A novel single-cell staining procedure performed in vivo under electrophysiological control: morpho-functional features of juxtacellularly labeled thalamic cells and other central neurons with biocytin or neurobiotin. J Neurosci Methods 65:113-136. CrossRef Medline

Platt NJ, Gispert S, Auburger G, Cragg SJ (2012) Striatal dopamine transmission is subtly modified in human A53Talpha-synuclein overexpressing mice. PLoS One 7:e36397. CrossRef Medline

Roeper J, Ashcroft F (1994) Oxidative stress reduces fast inactivation of an a-current in isolated dopaminergic substantia-nigra neurons from rat. J Physiol-London 475P:P144.

Satake W, Nakabayashi Y, Mizuta I, Hirota Y, Ito C, Kubo M, Kawaguchi T, Tsunoda T, Watanabe M, Takeda A, Tomiyama H, Nakashima K, Hasegawa K, Obata F, Yoshikawa T, Kawakami H, Sakoda S, Yamamoto M, Hattori N, Murata M, et al. (2009) Genome-wide association study identifies common variants at four loci as genetic risk factors for Parkinson's disease. Nat Genet 41:1303-1307. CrossRef Medline
Schiemann J, Schlaudraff F, Klose V, Bingmer M, Seino S, Magill PJ, Zaghloul KA, Schneider G, Liss B, Roeper J (2012) K-ATP channels in dopamine substantia nigra neurons control bursting and novelty-induced exploration. Nat Neurosci 15:1272-1280. CrossRef Medline

Siddiqui A, Chinta SJ, Mallajosyula JK, Rajagopolan S, Hanson I, Rane A, Melov S, Andersen JK (2012) Selective binding of nuclear alphasynuclein to the PGClalpha promoter under conditions of oxidative stress may contribute to losses in mitochondrial function: implications for Parkinson's disease. Free Radic Biol Med 53:993-1003. CrossRef Medline

Simon-Sanchez J, Schulte C, Bras JM, Sharma M, Gibbs JR, Berg D, PaisanRuiz C, Lichtner P, Scholz SW, Hernandez DG, Krüger R, Federoff M, Klein C, Goate A, Perlmutter J, Bonin M, Nalls MA, Illig T, Gieger C, Houlden H, et al. (2009) Genome-wide association study reveals genetic risk underlying Parkinson's disease. Nat Genet 41:1308-1312. CrossRef Medline

Subramaniam M, Kern B, Vogel S, Klose V, GS and JR (2014) Selective increase of in vivo firing frequencies in DA SN neurons after proteasome inhibition in the ventral midbrain. Eur J Neurosci. Advance online publication. CrossRef Medline

Sulzer D (2007) Multiple hit hypotheses for dopamine neuron loss in Parkinson's disease. Trends Neurosci 30:244-250. CrossRef Medline

Surmeier DJ, Guzman JN, Sanchez-Padilla J (2010) Calcium, cellular aging, and selective neuronal vulnerability in Parkinson's disease. Cell Calcium 47:175-182. CrossRef Medline

Surmeier DJ, Schumacker PT (2013) Calcium, bioenergetics and neuronal vulnerability in Parkinsons disease. J Biol Chem 288:10736-10741 CrossRef Medline

Topf N, Jenkins A, Baron N, Harrison NL (2003) Effects of isoflurane on gamma-aminobutyric acid type A receptors activated by full and partial agonists. Anesthesiology 98:306-311. CrossRef Medline

Ungless MA, Magill PJ, Bolam JP (2004) Uniform inhibition of dopamine neurons in the ventral tegmental area by aversive stimuli. Science 303 : 2040-2042. CrossRef Medline

Vekrellis K, Xilouri M, Emmanouilidou E, Rideout HJ, Stefanis L (2011) Pathological roles of alpha-synuclein in neurological disorders. Lancet Neurol 10:1015-1025. CrossRef Medline

Venda LL, Cragg SJ, Buchman VL, Wade-Martins R (2010) $\alpha$-Synuclein and dopamine at the crossroads of Parkinson's disease. Trends Neurosci 33:559-568. CrossRef Medline

Wang G, Covarrubias M (2006) Voltage-dependent gating rearrangements in the intracellular T1-T1 interface of a K+ channel. J Gen Physiol 127: 391-400. CrossRef Medline

Wang G, Shahidullah M, Rocha CA, Strang C, Pfaffinger PJ, Covarrubias M (2005) Functionally active $t 1-t 1$ interfaces revealed by the accessibility of intracellular thiolate groups in kv4 channels. J Gen Physiol 126:55-69. CrossRef Medline

Wang G, Strang C, Pfaffinger PJ, Covarrubias M (2007) Zn2+-dependent redox switch in the intracellular T1-T1 interface of a $\mathrm{Kv}$ channel. J Biol Chem 282:13637-13647. CrossRef Medline 